\title{
Numerical Analysis of Electrohydrodynamic Flow in a Circular Cylindrical Conduit by Using Neuro Evolutionary Technique
}

\author{
Naveed Ahmad Khan ${ }^{1}\left(\mathbb{D}\right.$, Muhammad Sulaiman ${ }^{1, *}$, , Carlos Andrés Tavera Romero ${ }^{2}(\mathbb{D}$ \\ and Fawaz Khaled Alarfaj ${ }^{3}$ (D) \\ 1 Department of Mathematics, Abdul Wali Khan University, Mardan 23200, Pakistan; \\ ahmednaveed854477@gmail.com \\ 2 COMBA R\&D Laboratory, Faculty of Engineering, Universidad Santiago de Cali, Cali 76001, Colombia; \\ carlos.tavera00@usc.edu.co \\ 3 Department of Computer and Information Sciences, Imam Mohammad Ibn Saud Islamic University, \\ Riyadh 11564, Saudi Arabia; fkarfaj@imamu.edu.sa \\ * Correspondence: msulaiman@awkum.edu.pk
}

Citation: Khan, N.A.; Sulaiman, M.; Tavera Romero, C.A.; Alarfaj, F.K.

Numerical Analysis of

Electrohydrodynamic Flow in a Circular Cylindrical Conduit by Using Neuro Evolutionary Technique. Energies 2021, 14, 7774. https:// doi.org/10.3390/en14227774

Academic Editors: Dimitris Drikakis and Gavin Tabor

Received: 20 September 2021

Accepted: 8 November 2021

Published: 19 November 2021

Publisher's Note: MDPI stays neutral with regard to jurisdictional claims in published maps and institutional affiliations.

Copyright: (C) 2021 by the authors. Licensee MDPI, Basel, Switzerland. This article is an open access article distributed under the terms and conditions of the Creative Commons Attribution (CC BY) license (https:/ / creativecommons.org/licenses/by/ $4.0 /)$.

\begin{abstract}
This paper analyzes the mathematical model of electrohydrodynamic (EHD) fluid flow in a circular cylindrical conduit with an ion drag configuration. The phenomenon was modelled as a nonlinear differential equation. Furthermore, an application of artificial neural networks (ANNs) with a generalized normal distribution optimization algorithm (GNDO) and sequential quadratic programming (SQP) were utilized to suggest approximate solutions for the velocity, displacements, and acceleration profiles of the fluid by varying the Hartmann electric number $\left(\mathrm{Ha}^{2}\right)$ and the strength of nonlinearity $(\alpha)$. ANNs were used to model the fitness function for the governing equation in terms of mean square error (MSE), which was further optimized initially by GNDO to exploit the global search. Then SQP was implemented to complement its local convergence. Numerical solutions obtained by the design scheme were compared with RK-4, the least square method (LSM), and the orthonormal Bernstein collocation method (OBCM). Stability, convergence, and robustness of the proposed algorithm were endorsed by the statistics and analysis on results of absolute errors, mean absolute deviation (MAD), Theil's inequality coefficient (TIC), and error in Nash Sutcliffe efficiency (ENSE).
\end{abstract}

Keywords: electrohydrodynamic flow; circular cylindrical conduit; Hartmann electric number; artificial neural networks; generalized normal distribution optimization; neuro soft computing

\section{Introduction}

Electro fluid systems have attracted a large number of researchers in recent years due to their wide range of applications in engineering and industrial processes [1,2]. The influence of electric fields on fluids has been studied from a theoretical point of view in the recent past to create novel processes [3]. The interaction of hydrodynamics and electrodynamics in dielectric fluid flow in the presence of an electric field is referred to as electrohydrodynamics (EHD) $[4,5]$. It is the study of the motion of ionized fluid and controls transportation phenomena in fluid flow. EHD flows have a variety of applications in different fields such as electrostatic precipitators [6,7], designs of dielectric pumps [8], the flow of ions in diverter tokamak reactors [9], thermal management of microelectronics by using electro gas dynamical pumps [10], application of Taylor cone EHD jets for electrospray of liquid atomization [11], electro-fluid control of colloidal particles near electrodes [12], MEMS devices [13], inkjet devices [14], propulsion of small scale naval vessels [15], processing of nickel particle flows and their regulation in medical powder [16], etc.

McKee et al. [17] in 1997, for the first time, dealt with the electrohydrodynamic (EHD) flow of fluid in an ion drag configuration in a circular cylindrical conduit, which was governed by a nonlinear boundary value problem (BVP). They studied velocity profiles 
by obtaining perturbation solutions due to variations in small and large parameters governing the nonlinear problem. For large values of strength of nonlinearity $(\alpha)$, they used the combination of Ranga-Kutta methods and the finite difference method to calculate the numerical solutions for fluid velocity. Further, they concluded that for $\alpha \gg 1$ and $\alpha \ll 1$, the perturbation solutions were expanded to series solutions with $\mathrm{O}(1)$ and $\mathrm{O}\left(n^{\alpha}\right)$, respectively. Paullet [18], in 1999, proved the existence and authentication of solutions to the EHD flow of fluid in the cylindrical conduit. The results obtained by [18] for a larger value of $\alpha$ were qualitatively different from those obtained by [17]. Statistics showed that for $\alpha \gg 1$ results by [17] diverged because the perturbation solutions were expanded to $\mathrm{O}(1 / \alpha)$ instead of $\mathrm{O}(1)$ [18]. Mastroberardino [19] used the homotopy perturbation method to find analytical solutions for the velocity profile of EHD flow by varying the values of the nonlinearity parameter and the Hartmann electrical number. Panday [20] used two semianalytical techniques based on an optimal homotopy analysis method and the homotopy asymptotic method to solve the EHD problem by varying different values of the parameters. Further, [21] developed a new homotopy perturbation method (NHPM) that depended on two components of homoptopy series to study the EHD flow equation. Moghtadaei [22] used the hybridization of the spectral homotopy analysis method (SHAM) and the spectral collocation method (SCM) to investigate the EHD problem in ion drag configuration. Pradip Roul $[23,24]$ developed a new approximate method, namely the discrete Adomian decomposition method (DADM), to approximate the solution of a strongly nonlinear singular boundary value problem describing the electrohydrodynamic flow of a fluid in an iron drag configuration in a circular cylindrical conduit. Further, [25] used the differential transformation method to find an analytical solution for the velocity profile by varying the strength of nonlinearity $(0<\alpha<1)$. This assumption helped overcome the limitation of nonlinearity and singularity. Various numerical and analytical techniques such as the pseudospectral collocation method [26], spectral collocation method [27], discrete optimized homotopy analysis method (DOHAM) [28], DTM-Pade' approximation [29], least square method [30], Galerkin Method, Collocation Method [31] and optimal B-spline collocation method [32,33] have been used. The electrohydrodynamic (EHD) flow of fluid has been studied by various numerical and analytical approaches but due to the singularity and nonlinearity in the nature of its mathematical model, it is difficult for traditional techniques to find its approximate solutions. In this paper, we have solved the EHD flow of fluid in a circular cylindrical conduit with an ion drag configuration numerically by applying a stochastic technique based on artificial neural networks (ANNs). In recent times, ANNs have been widely used to solve the number of problems arising in petroleum engineering [34], thermal engineering [35-38], civil engineering [39], biological models [40,41], and wire coating dynamics [42]. These applications of stochastic techniques are motivating factors for authors to analyze, explore, and investigate a nonlinear singular model of the EHD flow of fluid. In this paper, we designed an evolutionary soft computing technique to optimize the mathematical model of the electrohydrodynamic flow of fluid with an ion drag configuration by using the hybridization of the generalized normal distribution optimization (GNDO) algorithm and sequential quadratic programming (SQP). Contributions of the given study are highlighted through the following salient features:

- This paper developed a neuroevolutionary soft computing paradigm to analyze the mathematical model of electrohydrodynamic (EHD) flow of fluid in the circular cylindrical conduit by exploiting the global search efficiency of GNDO and local search support of SQP. The design technique is named ANNs-GNDO-SQP.

- The proposed algorithm was implemented on the EHD problem to study the effect of variations in the nonlinearity parameter and the Hartmann electrical number on $w^{*}\left(r^{*}\right), w^{* \prime}\left(r^{*}\right)$, and $w^{* \prime \prime}\left(r^{*}\right)$.

- Approximate solutions obtained by the ANNs-GNDO-SQP algorithm were compared with RK-4, the least square method (LSM), and the orthonormal Bernstein collocation method (OBCM). 
- $\quad$ The performance of the design paradigm was validated through statistics of the fitness function, absolute errors, mean absolute deviation, error in Nash Sutcliffe efficiency, and Theil's inequality coefficient.

\section{Problem Formulation}

In this section, we present the mathematical overview of the governing equation. Consider a circular cylindrical conduit in an axisymmetric coordinate system of radius $(r)$ with insulating conduit walls, as illustrated though Figure 1 . An electric field $\left(\vec{E}_{0}\right)$ is produced in fluid by applying voltage $(V)$. Current density in a dielectric medium for a single ionized particle is defined as $[20,43]$

$$
\vec{l}=\rho_{f}\left[\vec{v}+K \vec{E}_{0}\right],
$$

where $K$ is the ion mobility, and $\rho_{f}$ denotes the charge density of ions in fluid. The velocity of the fluid in generalized form is given as

$$
\vec{l}=(0,0, l(r)), \vec{v}=(0,0, w(r)), \rho_{f}=\rho(r),
$$

where, the pressure gradient $(\partial p / \partial z)$ is assumed to be constant. By using Equation (2), the Naiver Stokes equation reduces to

$$
r \frac{\partial p}{\partial z}=r \rho_{f} E_{0}+\mu \frac{d}{d r}\left[r \frac{d w}{d r}\right],
$$

where $\mu$ denotes the viscosity (dynamic) of the EHD fluid. The velocity profiles of fluid depend on time scales such as $U$ and $L$ which determine the coupling between ions and fluid.

$$
t_{c}=\frac{\varepsilon_{0}}{K \rho_{0}}, t_{f}=\frac{L}{U}
$$

where, $\varepsilon_{0}$ denotes the permittivity constant of free space, $t_{c}$ is the relation time of charge, $t_{f}$ is the time of fluid transport, and $\rho_{0}$ denotes the charge density at the inlet screen. From Equation (1), assuming that $l(z=0)=l_{0}$ the charge density can be defined as

$$
\rho_{f}(r)=\frac{l_{0}}{K E_{0}+w(r)} .
$$

In order to calculate the velocity profile of the EHD fluid, Equations (3)-(5) are integrated to obtain a nonlinear differential equation which is given as

$$
\frac{\partial p}{\partial z}=\frac{r l_{0} E_{0}}{K E_{0}+w}+\frac{\mu}{r} \frac{d}{d r}\left[r \frac{d w}{d r}\right],
$$

with the boundary conditions defined at the center and wall of a conduit as

$$
w \prime(r)=0 \text { at } r=0 ; \quad w=0 \text { at } r=a .
$$

Since, velocity is bounded at $r=0$, defining dimensionless variables $r^{*}=r / a$ and $w^{*}=-\left(w / K E_{0} \alpha\right)$ we obtain,

$$
\frac{d^{2} w^{*}}{d r^{* 2}}+\frac{1}{r^{*}} \frac{d w^{*}}{d r^{*}}+H a^{2}\left[1-\frac{w^{*}}{1-\alpha w^{*}}\right]=0
$$

with

$$
w^{* \prime}\left(r^{*}\right)=0 \text { at } r^{*}=0 ; \quad w^{*}=0 \text { at } r^{*}=1,
$$




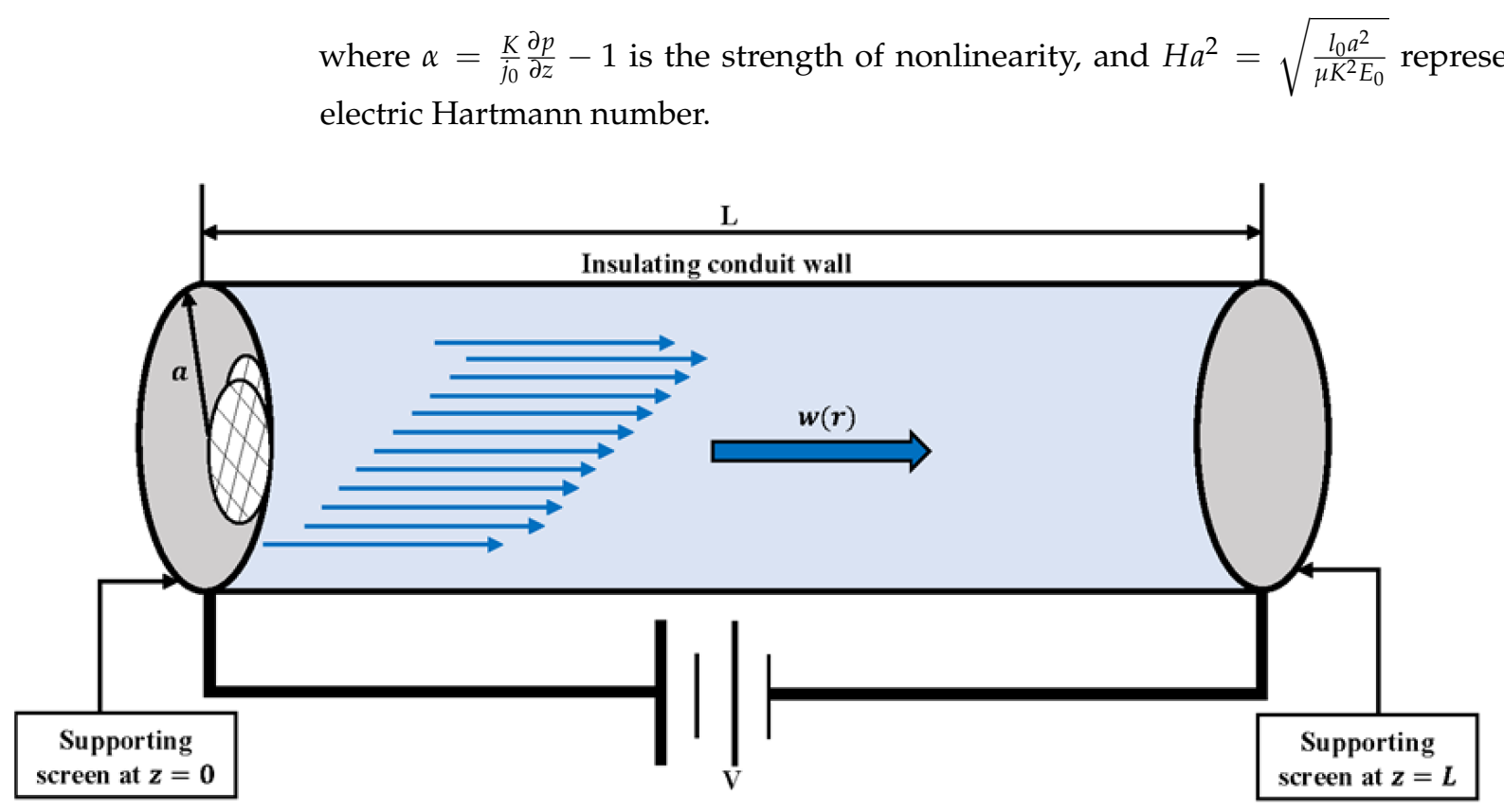

Figure 1. Schematic of the EHD flow in a circular cylindrical conduit.

\section{Design Methodology}

In this section, the structure of the design methodology is presented to solve the EHD problem with ion drag configuration. The methodology consisted of two steps. Initially, an approximate solution model for differential equations based on mean square error was constructed. Secondly, an optimization process of the fitness function was carried out by utilizing the hybridization of GNDO and SQP.

\subsection{ANN Modeling}

In this section, mathematical modeling of electrohydrodynamic (EHD) fluid flow in an ion drag configuration is emphasized by using artificial neural networks (ANNs). Feedforward ANNs were utilized to model approximate solutions $\hat{w}^{*}\left(r^{*}\right)$ for Equation (8) as

$$
\hat{w}^{*}\left(r^{*}\right)=\sum_{i=1}^{m} \alpha_{i}\left[f\left(\zeta_{i} r^{*}+\beta_{i}\right)\right]
$$

since, the $n t h$ order continuous derivative of Equation (10) exists, therefore, the first and second-order derivatives are defined as

$$
\begin{aligned}
& \frac{d \hat{w}^{*}\left(r^{*}\right)}{d r^{*}}=\sum_{i=1}^{m} \alpha_{i} \frac{d}{d r^{*}}\left[f\left(\zeta_{i} r^{*}+\beta_{i}\right)\right], \\
& \frac{d^{2} \hat{w}^{*}\left(r^{*}\right)}{d r^{* 2}}=\sum_{i=1}^{m} \alpha_{i} \frac{d}{d r^{*}}\left[f\left(\zeta_{i} r^{*}+\beta_{i}\right)\right],
\end{aligned}
$$

where, $W=(\alpha, \zeta, \beta)=\left(\alpha_{1}, \alpha_{2}, \ldots, \alpha_{m}, \zeta_{1}, \zeta_{2}, \ldots, \zeta_{m}, \beta_{1}, \beta_{2}, \ldots, \beta_{m}\right)$ are weights in ANNs architecture, $m$ represents the number of neurons and $f$ is a connection function or activation function. For instance, we consider the log-sigmoid function. Application of the log-sigmoid function will model Equations (10)-(12) as

$$
\begin{gathered}
\hat{w}^{*}\left(r^{*}\right)=\sum_{i=1}^{m} \alpha_{i}\left(\frac{1}{1+e^{-\left(\zeta_{i} r^{*}+\beta_{i}\right)}}\right), \\
\frac{d \hat{w}^{*}\left(r^{*}\right)}{d r^{*}}=\sum_{i=1}^{m} \alpha_{i} \zeta_{i}\left(\frac{e^{-\left(\zeta_{i} r^{*}+\beta_{i}\right)}}{\left(1+e^{-\left(\zeta_{i} r^{*}+\beta_{i}\right)}\right)^{2}}\right),
\end{gathered}
$$




$$
\frac{d^{2} \hat{w}^{*}\left(r^{*}\right)}{d r^{* 2}}=\sum_{i=1}^{m} \alpha_{i} \zeta_{i}^{2}\left(\frac{2 e^{-2\left(\zeta_{i} r^{*}+\beta_{i}\right)}}{\left(1+e^{-\left(\zeta_{i} r^{*}+\beta_{i}\right)}\right)^{3}}-\frac{e^{-\left(\zeta_{i} r^{*}+\beta_{i}\right)}}{\left(1+e^{-\left(\zeta_{i} r^{*}+\beta_{i}\right)}\right)^{2}}\right),
$$

ANNs architecture for the EHD flow of fluid in terms of input, hidden, and output layers is shown in Figure 2.

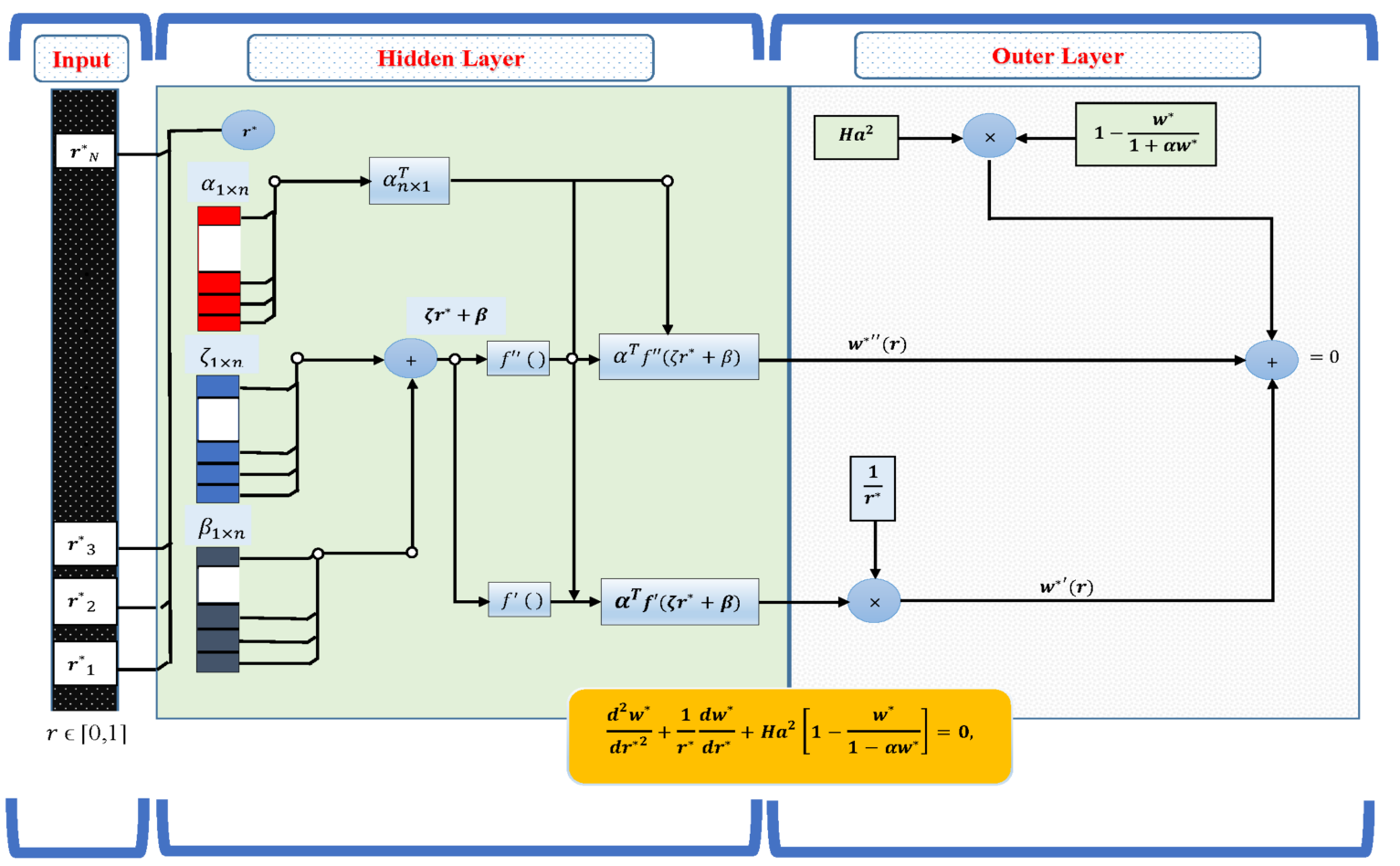

Figure 2. Architecture of ANNs for the mathematical model of the EHD flow of fluid.

\subsection{Formulation of the Fitness Function}

In this section, an objective function known as the fitness function is formulated in a mean square error sense for the nonlinear EHD problem.

$$
\text { Minimize } \Theta=\Theta_{1}+\Theta_{2},
$$

where, $\Theta_{1}$ and $\Theta_{2}$ are error functions corresponding to the nonlinear differential equation and boundary conditions, which are defined as

$$
\Theta_{1}=\frac{1}{N} \sum_{m=1}^{N}\left(\frac{d^{2} w_{m}^{*}}{d r^{* 2}}+\frac{1}{r^{*}} \frac{d w_{m}^{*}}{d r^{*}}+H a^{2}\left[1-\frac{w_{m}^{*}}{1-\alpha w_{m}^{*}}\right]\right)^{2},
$$

and

$$
\Theta_{2}=\frac{1}{2}\left(\left(\frac{d w^{*}}{d r^{*}}(0)-0\right)^{2}+\left(w^{*}(1)-0\right)^{2}\right),
$$

where, $N=\frac{1}{h}$, and $h$ represents the mesh points.

\subsection{Optimization Process}

In this section, an optimization process of ANNs based fitness function is incorporated by hybridization of the generalized normal distribution optimization algorithm and sequential quadratic programming. The detailed flow chart of the ANNs-GNDO-SQP algorithm is shown in Figure 3. 


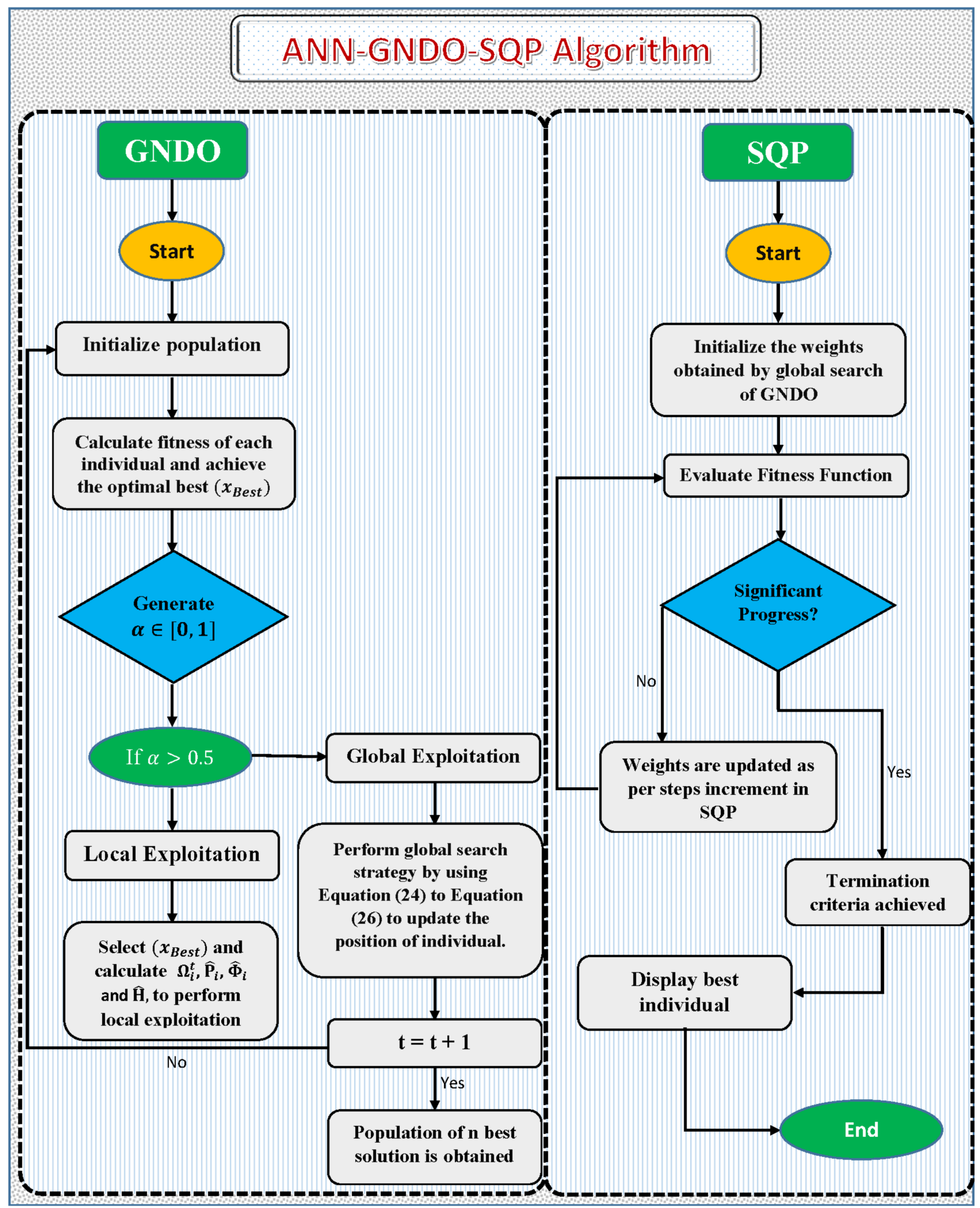

Figure 3. Workflow schematic of the proposed methodology for solving the EHD flow of fluid.

\subsubsection{Generalized Normal Distribution Optimization Algorithm}

The GNDO algorithm is a novel metaheuristic algorithm inspired by the classical generalized normal distribution theory [44]. It is a global search technique that is widely used for parameter extraction; unlike other metaheuristics, the GNDO algorithm is easy to 
implement requiring an initial population size and essential termination conditions. The working procedure of GNDO is based on two processes, which are explained as

- Exploitation

Exploitation refers to the process of finding the best solution around the search space consisting of the current positions of all individuals. A distribution model for optimization based on a relationship between the distribution of individuals and their normal distribution is given as

$$
\Omega_{i}^{t}=\hat{\Phi}_{i}+\hat{P}_{i} \times \hat{\mathrm{H}}, i=1,2,3, \ldots, N,
$$

where, $\Omega_{i}^{t}, \hat{P}_{i}, \hat{\Phi}_{i}$ and $\hat{\mathrm{H}}$, are the trial vector, standard variance, mean position (generalized), and penalty factor respectively. These parameters are defined as

$$
\begin{gathered}
\hat{\Phi}_{i}=\frac{1}{3}\left(x_{i}^{t}+x_{\text {Best }}^{t}+M\right), \\
M=\frac{\sum_{i=1}^{N} x_{i}^{t}}{N}, \\
\hat{P}_{i}=\sqrt{\frac{1}{3}\left[\left(x_{i}^{t}-\hat{\Phi}\right)^{2}+\left(x_{\text {Best }}^{t}-\hat{\Phi}\right)^{2}+(M-\hat{\Phi})^{2}\right]}, \\
\hat{\mathrm{H}}=\left\{\begin{array}{c}
\sqrt{-\log (h)} \times \cos \left(2 \pi h_{1}\right), \text { if } a \leq b \\
\sqrt{-\log (h) \times \cos \left(2 \pi h_{1}+\pi\right),}, \text { otherwise. }
\end{array}\right.
\end{gathered}
$$

here, $M$ denotes the mean position, $a, b, h$, and $h_{1}$ are random numbers from 0 to 1 and $\hat{\Phi}$ is the current position of the individual. $x_{i}^{t}$ is the $i t h$ individual, and $x_{B e s t}^{t}$ is the current best individual.

\section{- Exploration}

A process of searching entire population space for finding the global best solution is called exploration. In GNDO, exploration of search space is based on randomly selected individuals, which can be expressed as

$$
\Omega_{i}^{t}=x_{i}^{t}+\underbrace{(1-\beta) \times\left(\left|h_{2}\right| \times v_{2}\right)}_{\text {Global information sharing }}+\underbrace{\beta \times\left(\left|h_{3}\right| \times v_{1}\right),}_{\text {Local information sharing }}
$$

here, $\beta$ denotes the adjustment parameter, $h_{1}$ and $h_{2}$ are constants between 0 and 1 , and $v_{1}$ and $v_{2}$ are trial vectors that are defined as

$$
\begin{gathered}
v_{1}=\left\{\begin{array}{c}
x_{i}^{t}-x_{\mathrm{p}^{\prime}}^{t}, \text { if } f\left(x_{i}^{t}\right)<f\left(x_{a 1}^{t}\right), \\
x_{\mathrm{a} 2}^{t}-x_{i}^{t}, \text { otherwise, }
\end{array}\right. \\
v_{2}=\left\{\begin{array}{c}
x_{\mathrm{a} 2}^{t}-x_{\mathrm{a} 3}^{t}, \text { if } f\left(x_{\mathrm{p} 2}^{t}\right)<f\left(x_{\mathrm{a} 3}^{t}\right), \\
x_{\mathrm{a} 3}^{t}-x_{\mathrm{a} 2}^{t}, \text { otherwise. }
\end{array}\right.
\end{gathered}
$$

where, $a 1, a 2$, and $a 3$ are integers. An overview of the working procedure of GNDO is provided in pseudocode as Algorithm 1. Recently, the GNDO algorithm has been applied to study the parameter extraction photovoltaic models [44] and heat transfer in temperature fins [45].

\subsubsection{Sequential Quadratic Programming}

The SQP algorithm is a nonlinear programming technique that the research community has extensively used to solve a number of real world problems arising in different fields of engineering and applied mathematics. In this paper, the SQP algorithm was implemented to refine the process and weights obtained by the GNDO during the global search phase. Currently, SQP algorithms are used to find approximate solutions for two-block nonconvex constrained optimization problems [46], real power loss minimization in radial distribution 
systems [47], dynamic realtime optimization framework for cycling energy systems [48], measurement error in invariance testing [49], and maximum likelihood-based measurement noise covariance estimation [50].

In the present study, we exploited the global search ability of the GNDO algorithm with the sequential quadratic programming with the "fmincon" environment of MATLAB to calculate the approximate solutions using an ANN structure for the EHD flow of fluid. The detailed working procedure of the design algorithm is shown in Figure 3. The ANNGNDO-SQP algorithm has a simple structure and is easy to implement. GNDO updates the position of an individual using generalized normal distribution formula, and SQP complements its local convergence. The experimental analysis showed that the proposed algorithm converged to the best solutions for a number of real-world problems by training the weights from the interval $[-5,5]$. The convergence of design scheme was slightly affected by increasing the domain. The parameter settings for execution of the proposed algorithm are shown through Table 1.

Table 1. Parameter settings for the execution of the ANN-GNDO-SQP algorithm.

\begin{tabular}{cccc}
\hline Parameter & Setting & Parameter & Setting \\
\hline Algorithm & GNDO & Bounds [lower, upper] & {$[-5,5]$} \\
\hline Max. function evaluations & 125,000 & Search Agents & 60 \\
\hline X-tol. (TolX) & $10^{-18}$ & Tol. Fun. & $10^{-18}$ \\
\hline Algorithm & SQP & Bounds [lower, upper] & {$[-5,5]$} \\
\hline X-tol. (TolX) & $10^{-18}$ & Tol. Fun. & $10^{-18}$ \\
\hline Max. function evaluations & 150,000 & Max. Iterations & 1500 \\
\hline
\end{tabular}

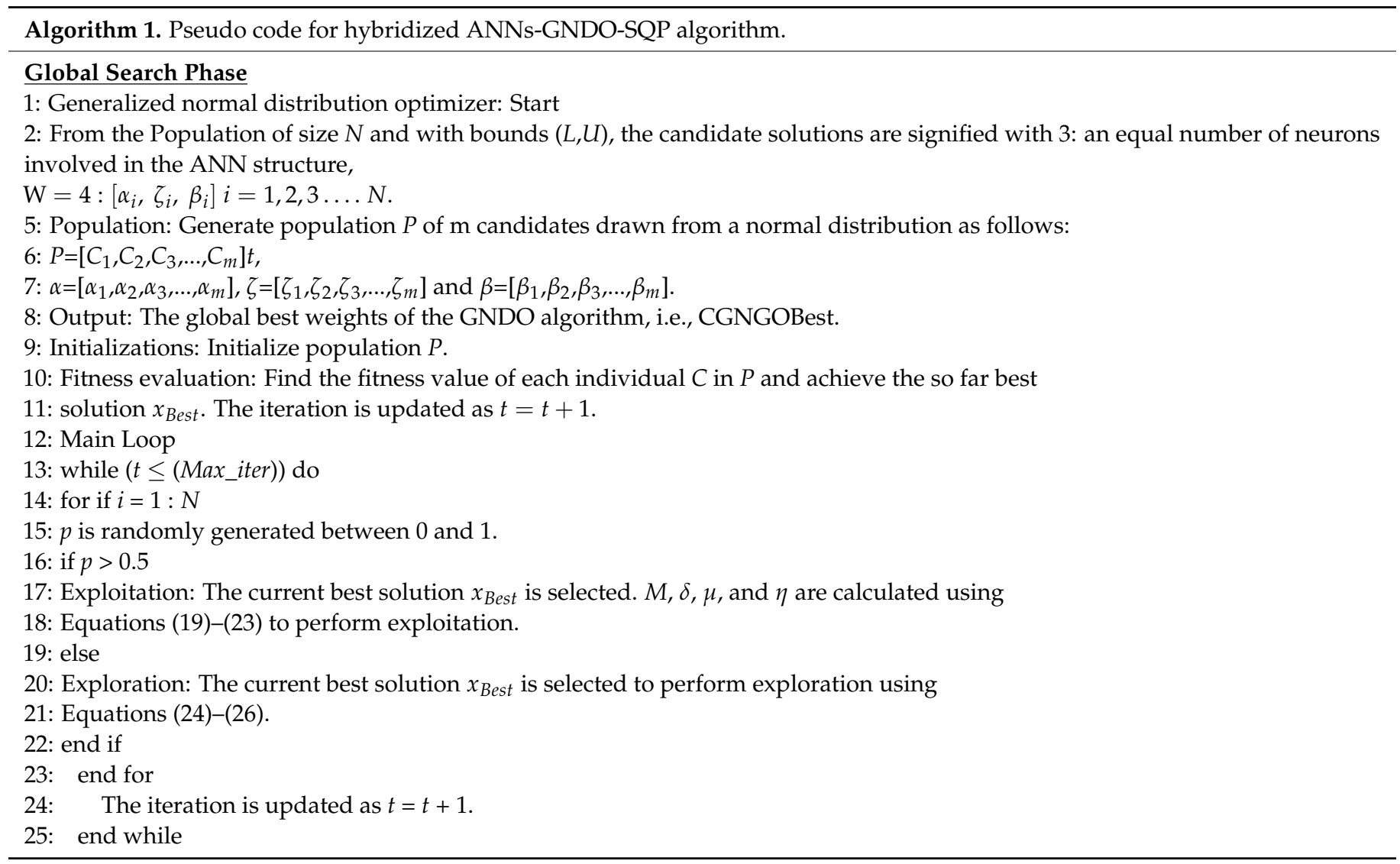


26: Termination: Stop GNDO for any of the following

- 27: Fitness $\Theta \leq 10^{-20}$, TolFunc $\leq 10^{-20}$.

- 28: Predefined iterations achieved.

29: Storage: Store $C G N G O_{\text {Best }}$, Fitness values, and Function evaluations.

30: Generalized normal distribution Optimizer: End

31: Local Search Phase

32: Sequential Quadratic Programming: Start

33: Inputs: CGNGOBest as initial point.

34: Output: Best weighted vector of GNDO-SQP, i.e., CGNGO-SQP

35: Initialization: Start-Point as CGNGOBest, assignment for bounds, iterations, and other settings.

36: Termination: Adaption process ends for any of the following conditions:

- $\quad$ 37: Fitness $\Theta \leq 10^{-20}$, TolFunc. $\leq 10^{-20}$.

- $\quad$ 38: Function Evaluation $\leq 200,000$

- 39: Maximum iterations $=1500$

40: Fitness evaluation: Evaluate fitness value $\Theta$ for each weight vector in $C$.

41: Fine-tuning: Use 'fmincon' for SQP. Update parameters of $C$ for each generation of SQP and 42: calculate fitness of modified $C$.

43: Storage: Accumulate weights vector CGNDO SQP, functions evaluations, fitness value, and 44: iterations.

45: Sequential quadratic programming: End

46: Data Generation: Simulate the above procedure 100 times to obtain data of fitness values and 47: unknown variables in ANN structure to solve nonlinear mathematical model of EHD flow of 48: fluid.

\section{Simulation and Discussion}

In this section, the design algorithm was implemented on the EHD flow to calculate the approximate solutions for the velocity, displacements, and acceleration profiles of the fluid by varying the Hartmann electric number $\left(\mathrm{Ha}^{2}\right)$ and the strength of nonlinearity $(\alpha)$. To demonstrate the accuracy of the proposed algorithm, the results were compared with the orthogonal Bernstein collocation method (OBCM) [20] the least square method (LSM) [30], and numerical solutions obtained by an implicit Runge-Kutta method (bvp5c), using MATLAB. Velocity profiles for different values of the Hartmann electric number and nonlinearity parameter are illustrated in Figures 4 and 5 respectively. From Figure 4, it can be seen that for fixed values of the nonlinearity parameter $(\alpha=0.5,1.0,1.5,2.0)$ an increase in the Hartmann electric number $\left(\mathrm{Ha}^{2}\right)$ causes an increase in the velocity profile, while Figure 5 shows that an increase in the nonlinearity parameter with a fixed Hartmann electric number $\left(\mathrm{Ha}^{2}=1,2,6,10\right)$ causes a decrease in the velocity profile of the EHD flow of fluid. The strength of nonlinearity has the adverse effect on the velocity profile against the Hartmann electric number. Moreover, it can be seen that a plug flow profile appears for small values of $\alpha$ with significantly large values of $\mathrm{Ha}^{2}$. Statistics of $w^{*}\left(r^{*}\right), w^{*^{\prime}}\left(r^{*}\right)$ and $w^{*^{\prime \prime}}\left(r^{*}\right)$ for different values of $H a^{2}$ and $\alpha$ are dictated in Tables 2 and 3 . The results for $w^{*}(0)$ obtained by the ANN-GNDO-SQP algorithm were compared with the orthogonal Bernstein collocation method (OBCM) and numerical solutions for $\alpha=0.5,1$ and 2 with $\mathrm{Ha}^{2}=1,2,6,10,20$, and 50 as shown in Table 4. Absolute errors in our solutions are plotted in Figure 6. The design scheme overlapped the analytical solution and had minimum absolute errors in comparison with the least square method (LSM) and OBCM as shown in Table 5. In order to show the superiority of ANN-GNDO-SQP, we investigated the effect of large values of $H a^{2}$ and $\alpha$ on the velocity of the fluid. Paullet [18] showed that solutions of Equation (8) with Equation (9) were bounded by $1 /(1+\alpha)$, so in case of $\alpha=4.0,8.0$ and 10.0, the results were bounded by $0.2,0.1$, and 0.09 . Due to strong nonlinearity in the differential equation Equation (8), numerical solver "bvp5c" could not calculate the numerical solution for large values of $\mathrm{Ha}^{2}$, and $\alpha$. Approximate solutions by the design algorithm for large values of $H a^{2}=205,075$ and $\alpha=4810$ are shown in Figure 7. In addition, Figure 8 dictates the influence of variations in $\alpha(20,50,100)$ on the velocity profile of the fluid with $H a^{2}=49$ and 81 . The results showed that for larger values of the Hartmann electric number, the solutions were essentially independent of $\mathrm{Ha}^{2}$ outside the boundary layers, i.e., for $\left(r^{*}<0.9\right)$. With the increasing value of $\alpha$ and $H a^{2}$, the problem stiffened, and the absolute errors decreased. 


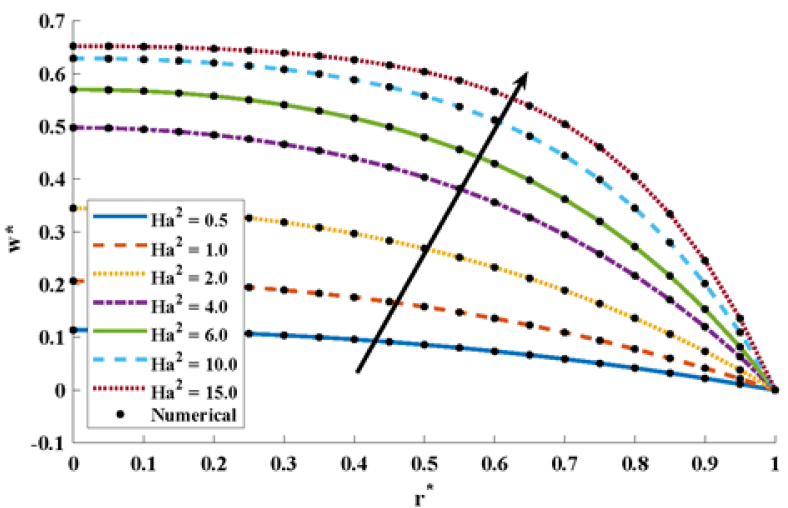

(a) $\alpha=0.5$

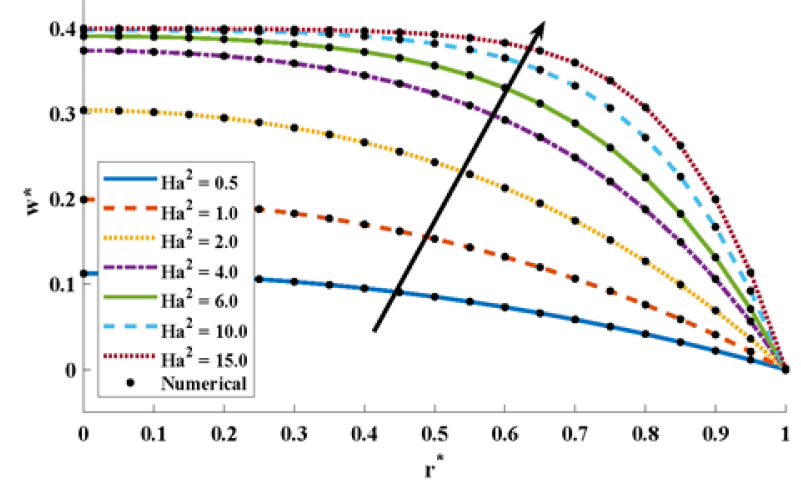

(c) $\alpha=1.5$

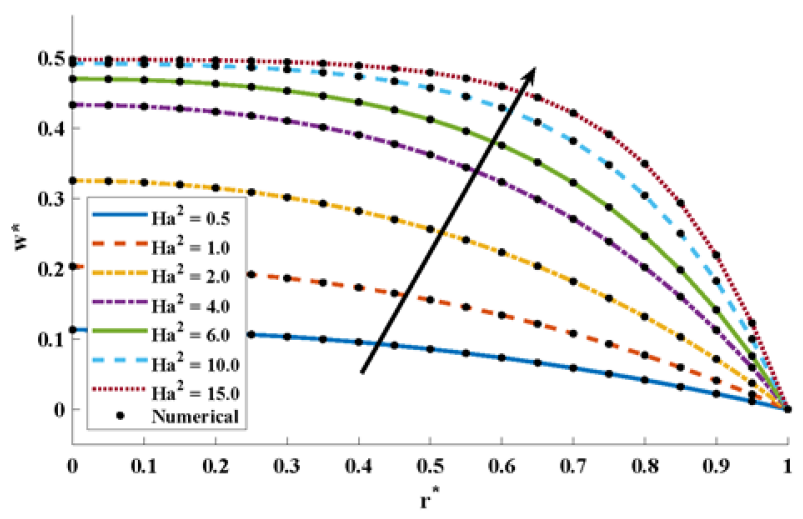

(b) $\alpha=1.0$

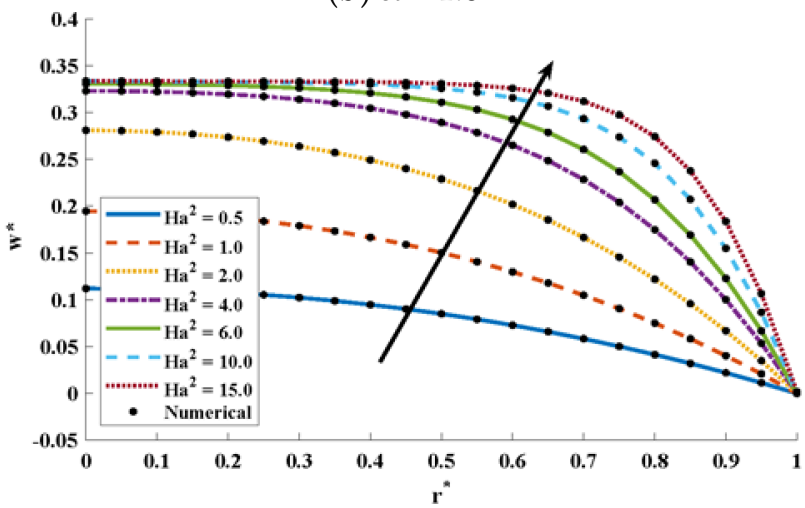

(d) $\alpha=2.0$

Figure 4. (a-d) Shows the plots of velocity profiles for variations in $H \mathrm{a}^{2}$ with different values of the nonlinearity parameter.

Table 2. The values of $w^{*}\left(r^{*}\right), w^{*^{\prime}}\left(r^{*}\right)$, and $w^{*^{\prime \prime}}\left(r^{*}\right)$ for different variations in the Hartmann electric number and nonlinearity parameter.

\begin{tabular}{|c|c|c|c|c|c|c|c|c|c|}
\hline \multirow[b]{2}{*}{$r^{*}$} & \multicolumn{3}{|c|}{$H a^{2}=0.5, \alpha=0.5$} & \multicolumn{3}{|c|}{$H a^{2}=1.0, \alpha=1.0$} & \multicolumn{3}{|c|}{$H a^{2}=2.0, \alpha=2.0$} \\
\hline & $w^{*}\left(r^{*}\right)$ & $w^{*^{\prime}}\left(r^{*}\right)$ & $w^{*^{\prime \prime}}\left(r^{*}\right)$ & $w^{*}\left(r^{*}\right)$ & $w^{*^{\prime}}\left(r^{*}\right)$ & $w^{* \prime \prime}\left(r^{*}\right)$ & $w^{*}\left(r^{*}\right)$ & $w^{* \prime}\left(r^{*}\right)$ & $w^{* \prime \prime}\left(r^{*}\right)$ \\
\hline 0.0 & 0.113707 & $-1.8 \times 10^{-5}$ & -0.21732 & 0.203413 & $-1.5 \times 10^{-6}$ & -0.37182 & 0.280907 & $-1.2 \times 10^{5}$ & -0.35570 \\
\hline 0.2 & 0.109323 & -0.04398 & -0.22213 & 0.195938 & -0.07504 & -0.38117 & 0.273559 & -0.07543 & -0.41490 \\
\hline 0.4 & 0.096052 & -0.08891 & -0.22754 & 0.173164 & -0.15355 & -0.40669 & 0.249274 & -0.17273 & -0.57393 \\
\hline 0.6 & 0.073667 & -0.13522 & -0.23622 & 0.134072 & -0.23872 & -0.44729 & 0.201780 & -0.31000 & -0.80677 \\
\hline 0.8 & 0.041820 & -0.18368 & -0.24908 & 0.077048 & -0.33327 & -0.49994 & 0.121959 & -0.49656 & -1.05659 \\
\hline 1.0 & 0 & -0.23505 & -0.26486 & 0 & -0.43924 & -0.56076 & $4.60 \times 10^{7}$ & -0.73015 & -1.26981 \\
\hline
\end{tabular}




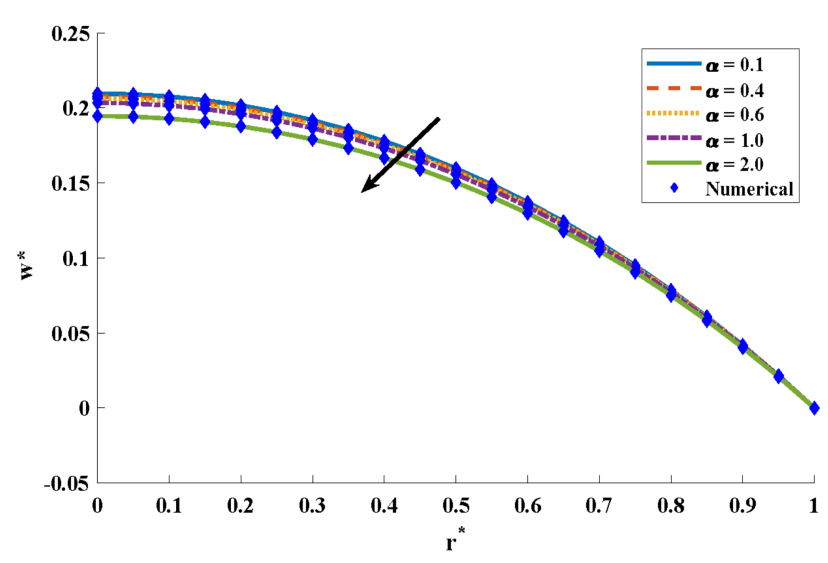

(a) $H a^{2}=1.0$

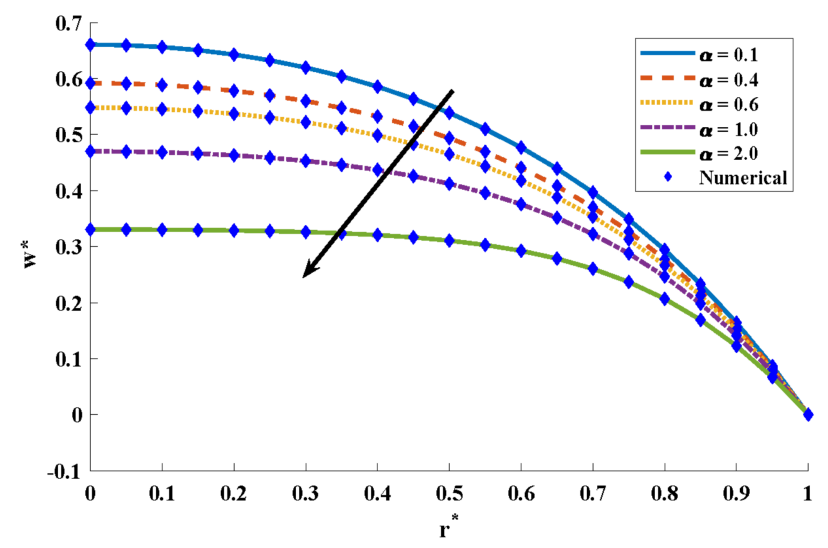

(c) $H a^{2}=6.0$

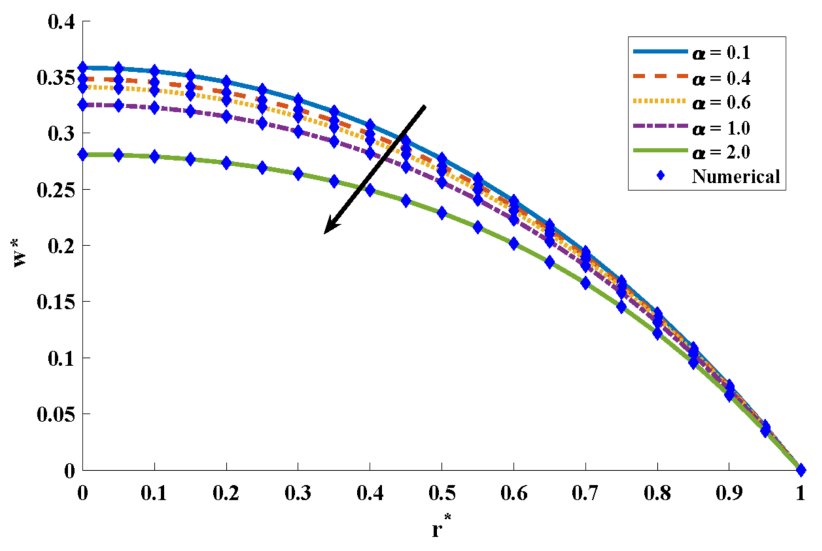

(b) $H a^{2}=2.0$

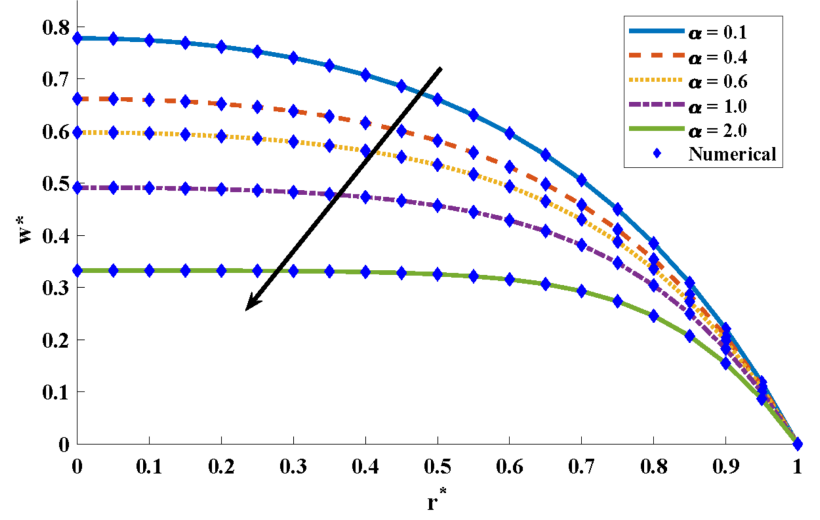

(d) $H a^{2}=10.0$

Figure 5. (a-d) shows the behavior of velocity profile under the influence of variations in the nonlinearity parameter for different values of $H a^{2}$.

Table 3. The values of $w^{*}\left(r^{*}\right), w^{*^{\prime}}\left(r^{*}\right)$, and $w^{*^{\prime \prime}}\left(r^{*}\right)$ for different variations in the Hartmann electric number and nonlinearity parameter.

\begin{tabular}{|c|c|c|c|c|c|c|c|c|c|}
\hline \multirow[b]{2}{*}{$r^{*}$} & \multicolumn{3}{|c|}{$H a^{2}=10, \alpha=0.6$} & \multicolumn{3}{|c|}{$H a^{2}=20, \alpha=1$} & \multicolumn{3}{|c|}{$H a^{2}=6.0, \alpha=2$} \\
\hline & $w^{*}\left(r^{*}\right)$ & $w^{*^{\prime}}\left(r^{*}\right)$ & $w^{*^{\prime \prime}}\left(r^{*}\right)$ & $w^{*}\left(r^{*}\right)$ & $w^{*^{\prime}}\left(r^{*}\right)$ & $w^{* \prime \prime}\left(r^{*}\right)$ & $w^{*}\left(r^{*}\right)$ & $w^{* \prime}\left(r^{*}\right)$ & $w^{* \prime \prime}\left(r^{*}\right)$ \\
\hline 0 & 0.59728 & -0.00023 & -0.32778 & 0.499319 & $7.7 \times 10^{-5}$ & -0.02410 & 0.330538 & 0.00015 & -0.07121 \\
\hline 0.2 & 0.590027 & -0.07732 & -0.48115 & 0.498676 & -0.00788 & -0.06765 & 0.328857 & -0.01924 & -0.14224 \\
\hline 0.4 & 0.562424 & -0.21495 & -0.97371 & 0.494716 & -0.03973 & -0.31859 & 0.320736 & -0.07203 & -0.45074 \\
\hline 0.6 & 0.493672 & -0.51095 & -2.13311 & 0.475000 & -0.19778 & -1.57414 & 0.292544 & -0.24034 & -1.36954 \\
\hline 0.8 & 0.335957 & -1.1406 & -4.36641 & 0.379997 & -0.91787 & -6.59433 & 0.206793 & -0.67357 & -3.04216 \\
\hline 1 & 0 & -2.33152 & -7.67030 & 0 & -3.24594 & -16.7489 & $-1.04 \times 10^{5}$ & -1.44529 & -4.55480 \\
\hline
\end{tabular}


Table 4. Comparison of values obtained by the ANN-GNDO-SQP algorithm for $w^{*}(0)$ with OBCM [20] and numerical solution for different values of nonlinearity parameter and Hartmann electric number.

\begin{tabular}{|c|c|c|c|c|c|c|c|c|c|}
\hline & & $\alpha=0.5$ & & & $\alpha=1$ & & & $\alpha=2$ & \\
\hline$H a^{2}$ & Numerical & ОВСМ & $\begin{array}{c}\text { ANN- } \\
\text { GNDO- } \\
\text { SQP }\end{array}$ & Numerical & ОВСМ & $\begin{array}{c}\text { ANN- } \\
\text { GNDO- } \\
\text { SQP }\end{array}$ & Numerical & ОВСМ & $\begin{array}{c}\text { ANN- } \\
\text { GNDO- } \\
\text { SQP }\end{array}$ \\
\hline 1 & 0.20700807 & 0.20700815 & 0.20700807 & 0.20341385 & 0.20341579 & 0.20341385 & 0.19459639 & 0.19459641 & 0.19459639 \\
\hline 2 & 0.34471303 & 0.34472730 & 0.34471303 & 0.32545491 & 0.32545427 & 0.32545491 & 0.28092892 & 0.28092892 & 0.28092892 \\
\hline 6 & 0.57002550 & 0.57002550 & 0.57002550 & 0.47017920 & 0.47017854 & 0.47017920 & 0.33053379 & 0.33053209 & 0.33053379 \\
\hline 10 & 0.62896071 & 0.62896071 & 0.62896071 & 0.49202969 & 0.49202968 & 0.49202969 & 0.33297071 & 0.33296462 & 0.33297071 \\
\hline 20 & 0.66043310 & 0.66043311 & 0.66043310 & 0.49932528 & 0.49932510 & 0.49932528 & 0.33332506 & 0.33339417 & 0.33332506 \\
\hline 50 & 0.66650870 & 0.66650608 & 0.66650870 & 0.49999536 & 0.49994762 & 0.49999536 & 0.33337147 & 0.33366547 & 0.33337147 \\
\hline
\end{tabular}

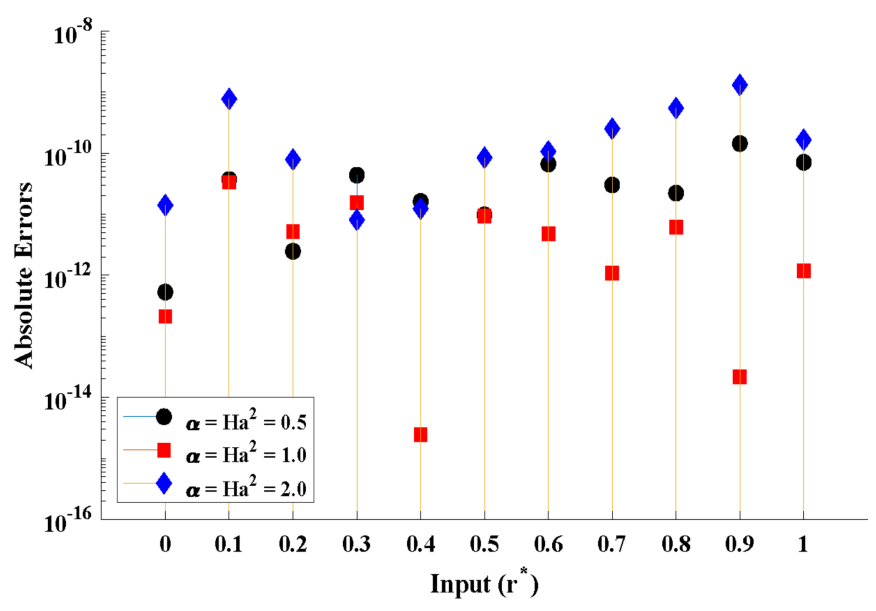

(a)

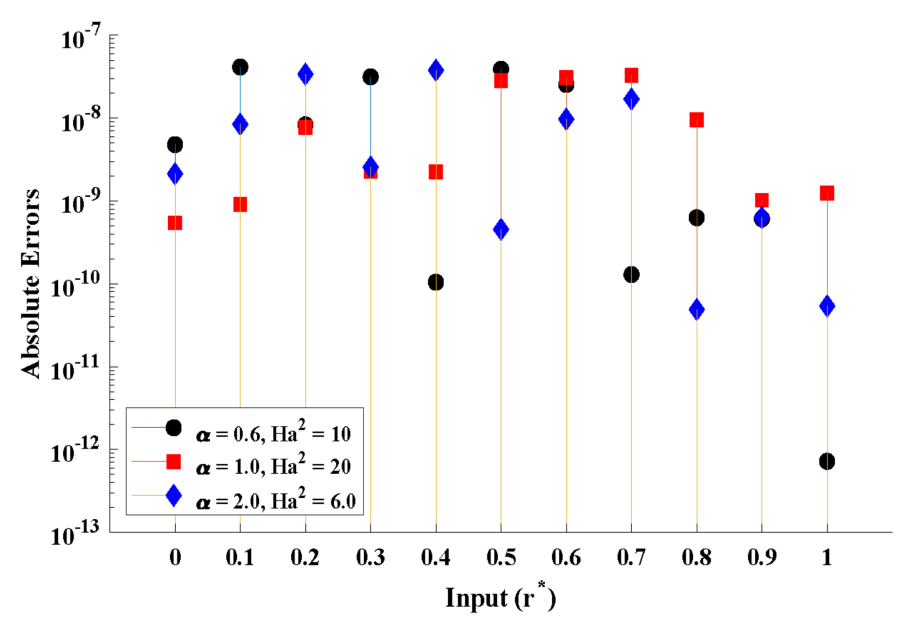

(b)

Figure 6. Absolute errors in our solutions obtained by the proposed algorithm for calculating $w^{*}\left(r^{*}\right)$ of the EHD flow of fluid for (a) same values of parameters and (b) different values of nonlinearity parameter and Hartmann electric.

Table 5. Comparison of absolute errors in our solutions obtained by the ANN-GNDO-SQP algorithm with the orthogonal Bernstein collocation method [20] and the least square method [30].

\begin{tabular}{ccccccc}
\hline \multicolumn{3}{c}{$\mathbf{H a}^{2}=\mathbf{0 . 5}, \boldsymbol{\alpha}=\mathbf{0 . 5}$} \\
\hline $\mathbf{t}$ & $\mathbf{L S M}$ & $\mathbf{O B C M}$ & ANN-GNDO-SQP & LSM & OBCM & ANN-GNDO-SQP \\
\hline 0 & $8.2992 \times 10^{-6}$ & $3.2023 \times 10^{-8}$ & $5.2979 \times 10^{-13}$ & $8.1842 \times 10^{-5}$ & $1.9384 \times 10^{-6}$ & $2.1171 \times 10^{-13}$ \\
0.1 & $6.3358 \times 10^{-6}$ & $3.1447 \times 10^{-8}$ & $3.6864 \times 10^{-11}$ & $6.4341 \times 10^{-5}$ & $1.9004 \times 10^{-6}$ & $3.3179 \times 10^{-11}$ \\
0.2 & $4.0286 \times 10^{-6}$ & $2.9727 \times 10^{-8}$ & $2.4690 \times 10^{-12}$ & $3.7985 \times 10^{-5}$ & $1.7900 \times 10^{-6}$ & $5.2357 \times 10^{-12}$ \\
0.3 & $2.4205 \times 10^{-6}$ & $2.7018 \times 10^{-8}$ & $4.3508 \times 10^{-11}$ & $2.1086 \times 10^{-5}$ & $1.6178 \times 10^{-6}$ & $1.5269 \times 10^{-11}$ \\
0.4 & $1.9436 \times 10^{-6}$ & $2.3538 \times 10^{-8}$ & $1.6113 \times 10^{-11}$ & $1.5688 \times 10^{-5}$ & $1.3997 \times 10^{-6}$ & $2.4361 \times 10^{-15}$ \\
0.5 & $2.0378 \times 10^{-6}$ & $1.9552 \times 10^{-8}$ & $9.7373 \times 10^{-12}$ & $1.6862 \times 10^{-5}$ & $1.1536 \times 10^{-6}$ & $9.3444 \times 10^{-12}$ \\
0.6 & $2.1622 \times 10^{-6}$ & $1.5327 \times 10^{-8}$ & $6.6434 \times 10^{-11}$ & $1.8463 \times 10^{-5}$ & $8.9738 \times 10^{-7}$ & $4.7320 \times 10^{-12}$ \\
0.7 & $2.0455 \times 10^{-6}$ & $1.1106 \times 10^{-8}$ & $3.0112 \times 10^{-11}$ & $1.6495 \times 10^{-5}$ & $6.4579 \times 10^{-7}$ & $1.0880 \times 10^{-12}$ \\
0.8 & $1.2410 \times 10^{-6}$ & $7.0791 \times 10^{-9}$ & $2.2059 \times 10^{-11}$ & $1.0793 \times 10^{-5}$ & $4.0942 \times 10^{-7}$ & $6.1656 \times 10^{-12}$ \\
0.9 & $1.0002 \times 10^{-6}$ & $3.3638 \times 10^{-9}$ & $1.4333 \times 10^{-10}$ & $5.5085 \times 10^{-6}$ & $1.9391 \times 10^{-7}$ & $2.1467 \times 10^{-14}$ \\
\hline
\end{tabular}




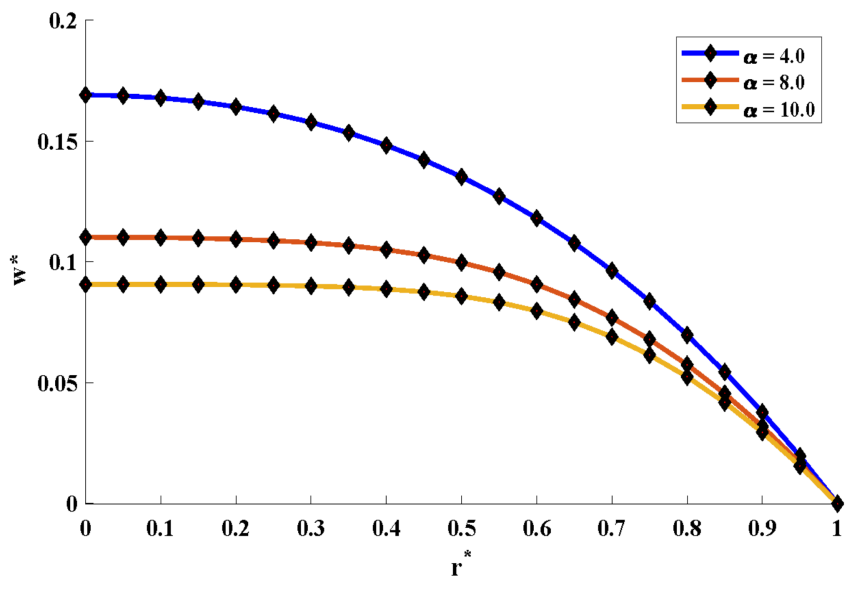

(a) $H a^{2}=1.0$

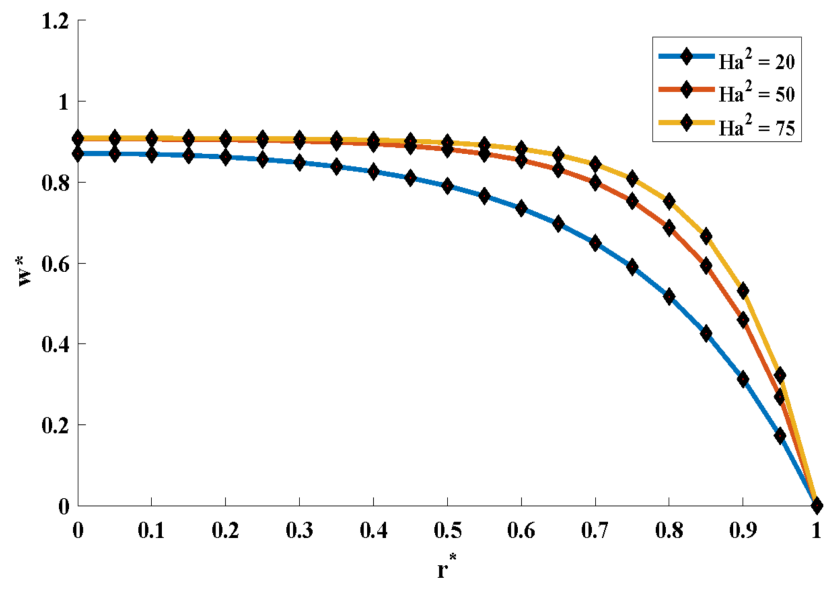

(b) $\alpha=0.1$

Figure 7. Results of velocity profile for the EHD flow of fluid with larger valu es of (a) the nonlinearity parameter and (b) $H \mathrm{a}^{2}$ achieved by the proposed algorithm.

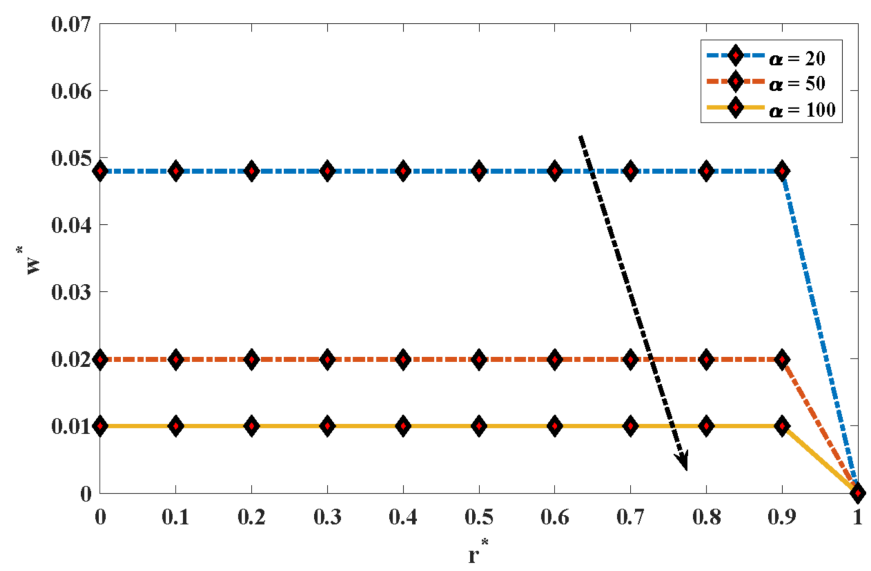

(a) Approximate Solution

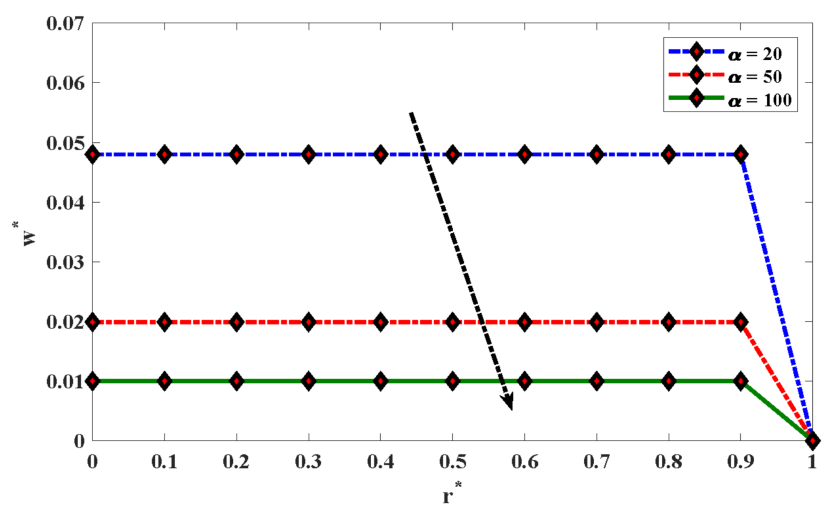

(c) Approximate Solution

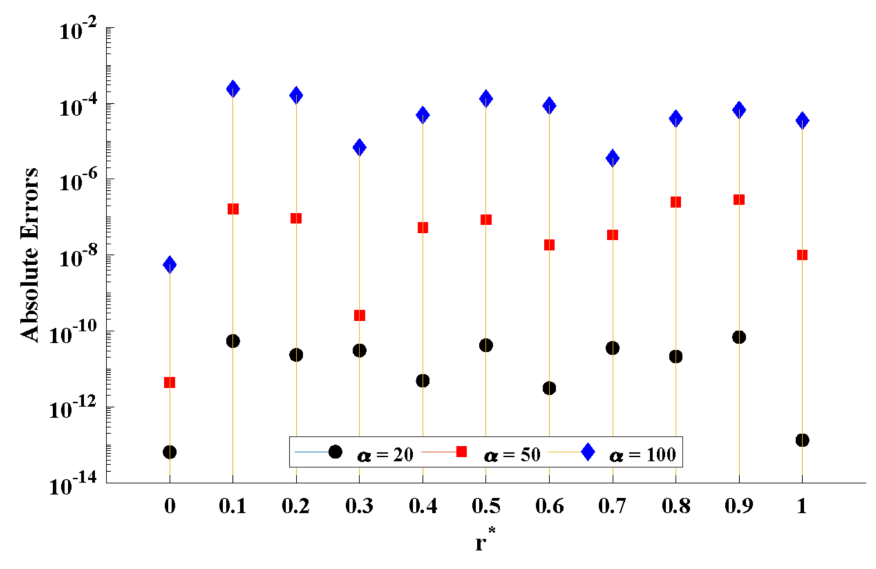

(b) Absolute Errors

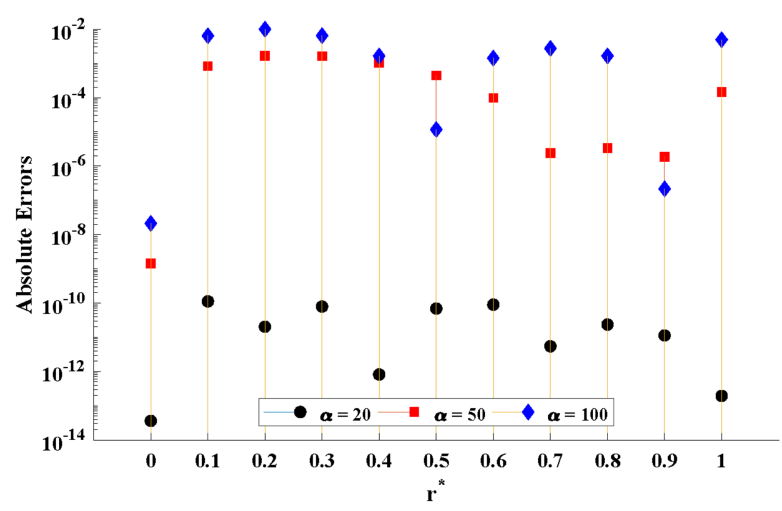

(d) Absolute Errors

Figure 8. $(\mathbf{a}-\mathbf{c})$ shows the approximate solutions and $(\mathbf{b}-\mathbf{d})$ dictates the absolute errors in results obtained by the ANNGNDO-SQP algorithm for Equation (8) with $H a^{2}=49$ and 81 . 
To check the performance and validity of the proposed ANN-GNDO-SQP algorithm, we defined different statistical operators along with their global form. The performance operators were fitness functions, Theil's inequality coefficient (TIC), mean absolute deviations (MAD), Nash Sutcliffe efficiency (NSE), and error in Nash Sutcliffe efficiency (ENSE). A mathematical formulation of these indices is defined as in [45].

$$
\begin{gathered}
\text { TIC }=\frac{\sqrt{\frac{1}{n} \sum_{i=1}^{n}\left(w\left(r_{i}\right)-\hat{w}^{*}\left(r_{i}^{*}\right)\right)^{2}}}{\sqrt{\frac{1}{n} \sum_{i=1}^{n}\left(w\left(r_{i}\right)\right)^{2}}+\sqrt{\frac{1}{n} \sum_{i=1}^{n}\left(\hat{w}^{*}\left(r_{i}^{*}\right)\right)^{2}}}, \\
M A D=\frac{1}{n} \sum_{i=1}^{n}\left(\left|w\left(r_{i}\right)-\hat{w}^{*}\left(r_{i}^{*}\right)\right|\right), \\
N S E=\left\{\begin{array}{c}
1-\frac{\sum_{i=1}^{n}\left(w,\left(r_{i}\right),-, \hat{w}^{*},\left(r_{i}^{*}\right)\right)^{2}}{\sum_{i=1}^{n}\left(w,\left(r_{i}\right),-, \bar{w},\left(r_{i}\right)\right)^{2}}, \quad \bar{w}\left(r_{i}\right)=\sum_{i=1}^{n}\left(w,\left(r_{i}\right)\right) \\
E N S E=[1-N S E],
\end{array}\right.
\end{gathered}
$$

where, $w\left(r_{i}\right)$ denotes the analytical solution, while $\hat{w}^{*}\left(r_{i}^{*}\right)$ represents the approximate solution by the ANN-GNDO-SQP algorithm. Global values of fitness function and performance indices can be calculated as

GFit $=\frac{1}{R_{n}} \sum_{j=1}^{R_{n}}$ Fit, GTIC $=\frac{1}{R_{n}} \sum_{j=1}^{R_{n}}$ TIC, GMAD $=\frac{1}{R_{n}} \sum_{j=1}^{R_{n}} M A D$, GENSE $=\frac{1}{R_{n}} \sum_{j=1}^{R_{n}}$ ENSE.

To study the optimization behavior of the objective function, 100 independent executions of the ANN-GNDO-SQP algorithm were carried out. Convergence of fitness function and TIC for Equation (17) depending on different values of $\alpha$ and $H a^{2}$ are shown in Figure 9. Fitness value for each case lay around $10^{-4}$ to $10^{-8}$ and $10^{-4}$ to $10^{-7}$, respectively. Average values of mean absolute deviations (MAD) of the solutions are shown in boxplots in Figure 10. Normal probability curves are plotted in Figure 11 for the values of ENSE. Furthermore, Table 6 depicts the stability analysis of the design algorithm. For 100 independent runs, the results in each run were in good agreement with the exact solutions. The accuracy of the design algorithm can be seen from values of ENSE that are approximately equal to zero for each case. Statistical analysis of the values of fitness function and performance indices are shown in Table 7. Global values of these indicators

\begin{tabular}{|c|c|c|c|c|c|c|c|c|c|c|c|c|}
\hline & \multirow[b]{2}{*}{$10^{-6}$} & \multicolumn{2}{|c|}{ Fitness Value } & \multicolumn{3}{|c|}{ MAD } & \multicolumn{3}{|c|}{ TIC } & \multicolumn{3}{|c|}{ ENSE } \\
\hline & & $10^{-7}$ & $10^{-8}$ & $10^{-4}$ & $10^{-5}$ & $10^{-6}$ & $10^{-4}$ & $10^{-5}$ & $10^{-6}$ & $10^{-6}$ & $10^{-7}$ & $10^{-8}$ \\
\hline$H a^{2}=\alpha=0.5$ & 100 & 100 & 100 & 100 & 100 & 89 & 100 & 99 & 47 & 100 & 90 & 50 \\
\hline$H a^{2}=\alpha=1.0$ & 100 & 93 & 48 & 100 & 100 & 92 & 100 & 43 & 12 & 50 & 34 & 14 \\
\hline$H a^{2}=\alpha=2.0$ & 99 & 55 & 38 & 100 & 83 & 23 & 99 & 57 & 19 & 76 & 47 & 22 \\
\hline$H a^{2}=6, \alpha=2$ & 75 & 16 & 2 & 100 & 61 & 0 & 100 & 68 & 2 & 81 & 29 & 6 \\
\hline$H a^{2}=20, \alpha=1$ & 75 & 10 & 0 & 100 & 48 & 0 & 100 & 57 & 3 & 68 & 15 & 3 \\
\hline
\end{tabular}
lay around $10^{-5}$ to $10^{-7}$ which shows the robustness and accuracy of the design scheme.

Table 6. Stability analysis in terms of fitness value, mean absolute deviations, Theil's inequality coefficient, and error in Nash Sutcliffe efficiency of the design algorithm when executed for 100 multiple runs. 


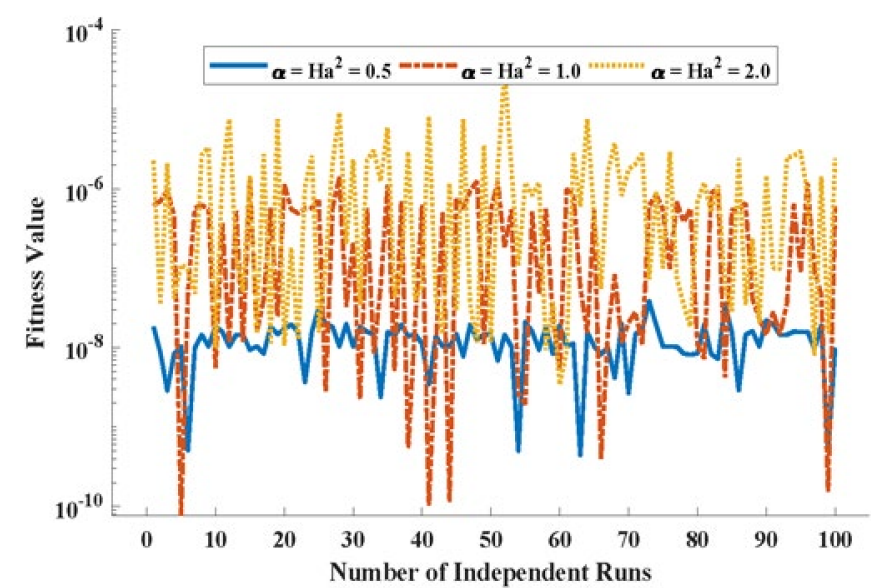

(a)

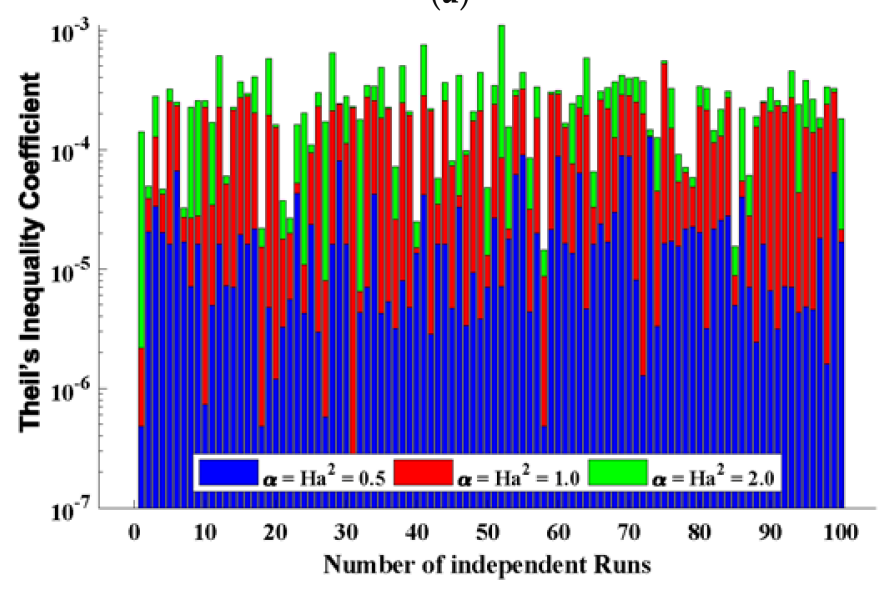

(c)

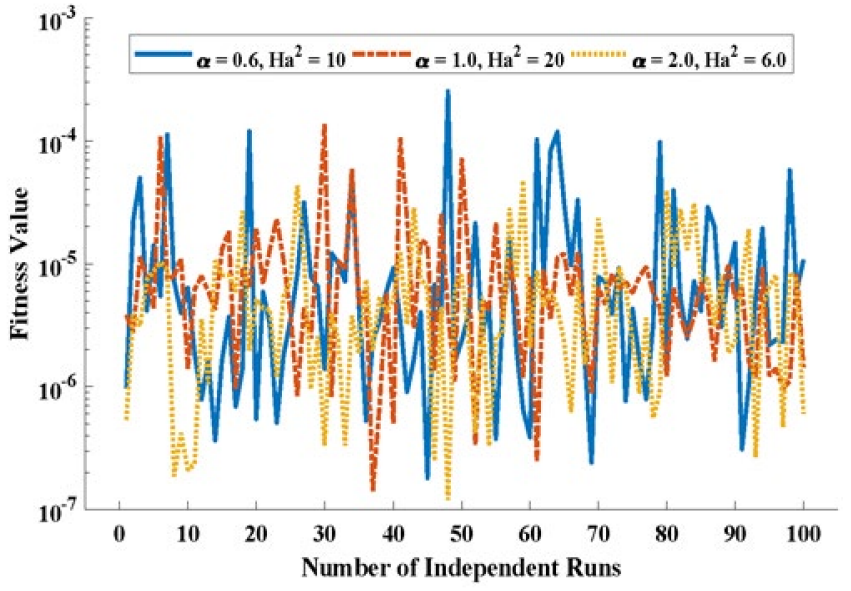

(b)

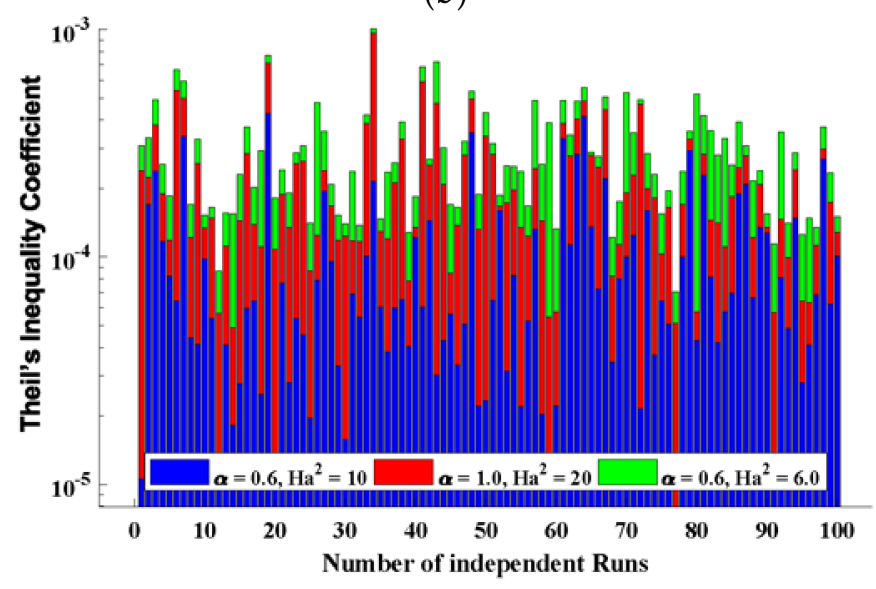

(d)

Figure 9. $(\mathbf{a}, \mathbf{b})$ shows the behavior of fitness value and $(\mathbf{c}, \mathbf{d})$ represents the convergence of the value of TIC during the optimization procedure of Equation (17), by the ANN-GNDO-SQP algorithm.

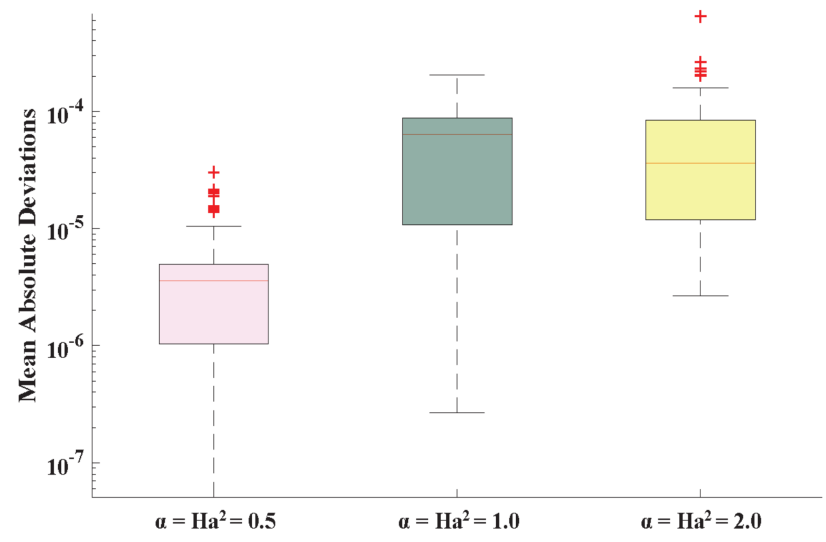

(a)

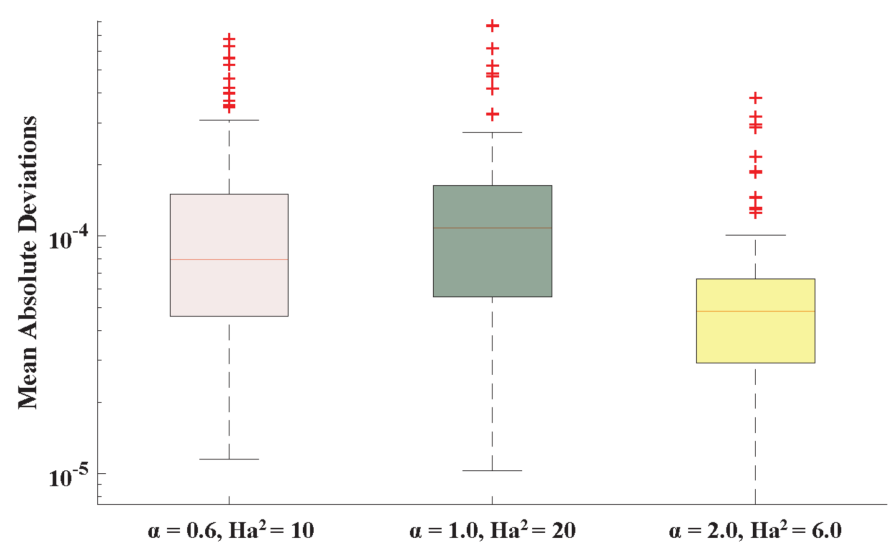

(b)

Figure 10. Boxplots for the analysis of the mean absolute deviation obtained by the design scheme during 100 independent runs for (a) same and (b) different values of nonlinearity parameter and Hartmann electric number. 


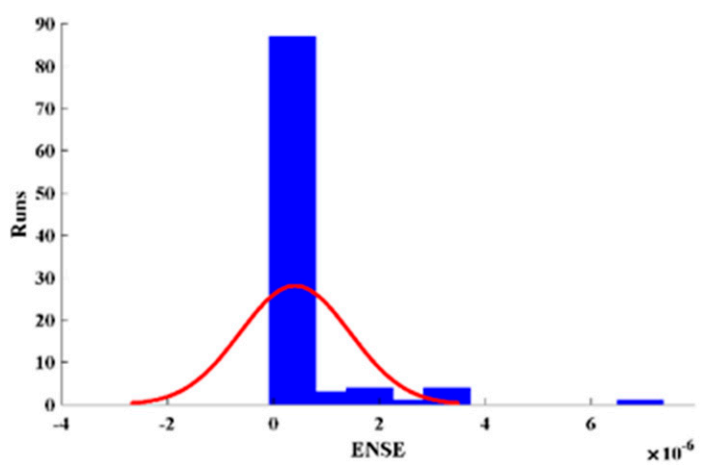

(a) $\alpha=H a^{2}=0.5$

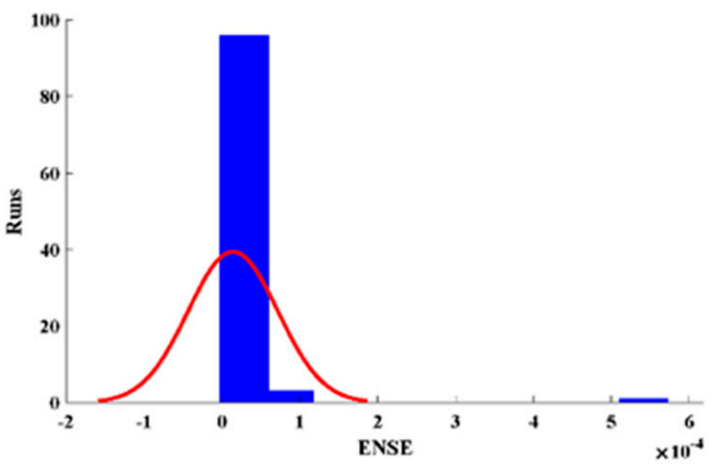

(c) $\alpha=H a^{2}=2.0$

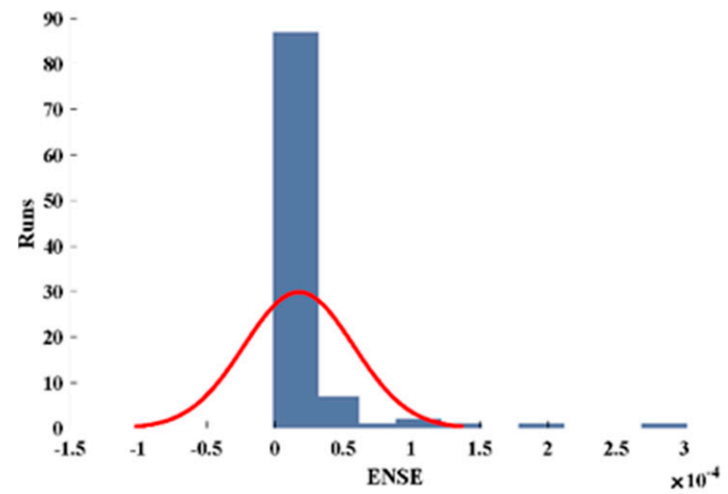

(e) $\alpha=1, H a^{2}=20$

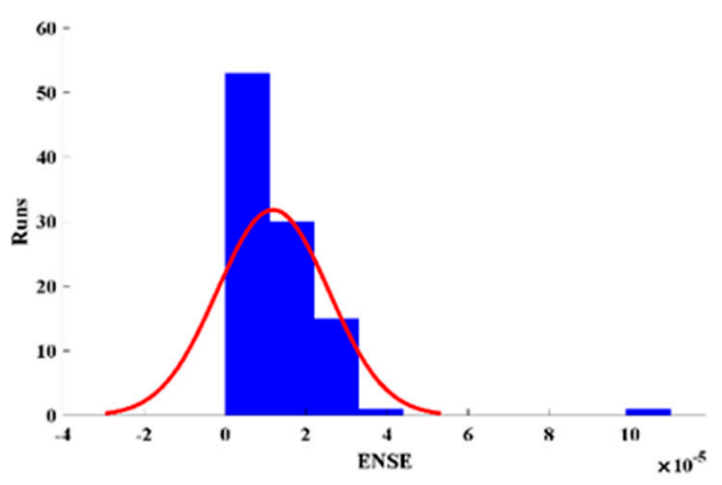

(b) $\alpha=H a^{2}=1.0$

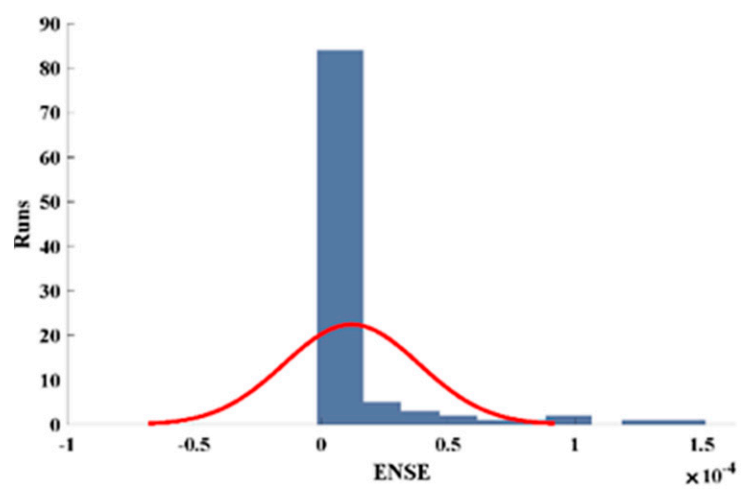

(d) $\alpha=0.6, H a^{2}=10$

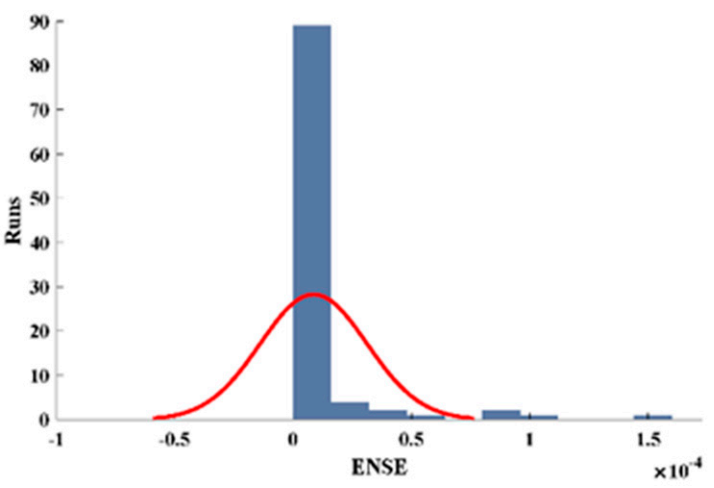

(f) $\alpha=2, H a^{2}=6$

Figure 11. (a-f) shows the normal probability curves for ENSE.

Table 7. Analysis of the values of fitness function and performance indices in term o minimum, mean, and standard deviations.

\begin{tabular}{|c|c|c|c|c|c|c|c|c|c|c|c|}
\hline & Fit & & & MAD & & & TIC & & & ENSE & \\
\hline Min. & Mean & Std. & Min. & Mean & Std. & Min. & Mean & Std. & Min. & Mean & Std. \\
\hline $4.44 \times 10^{-10}$ & $1.31 \times 10^{-8}$ & $6.52 \times 10^{-9}$ & $5.09 \times 10^{-8}$ & $4.55 \times 10^{-6}$ & $5.60 \times 10^{-6}$ & $1.95 \times 10^{-7}$ & $1.97 \times 10^{-5}$ & $2.40 \times 10^{-5}$ & $2.05 \times 10^{-11}$ & $4.11 \times 10^{-7}$ & $1.04 \times 10^{-6}$ \\
\hline $7.72 \times 10^{-11}$ & $3.74 \times 10^{-7}$ & $3.91 \times 10^{-7}$ & $2.67 \times 10^{-7}$ & $5.54 \times 10^{-5}$ & $4.10 \times 10^{-5}$ & $6.72 \times 10^{-7}$ & $1.32 \times 10^{-4}$ & $1.00 \times 10^{-4}$ & $1.78 \times 10^{-10}$ & $1.18 \times 10^{-5}$ & $1.38 \times 10^{-5}$ \\
\hline $3.39 \times 10^{-9}$ & $1.73 \times 10^{-6}$ & $3.66 \times 10^{-6}$ & $2.67 \times 10^{-6}$ & $6.08 \times 10^{-5}$ & $8.21 \times 10^{-5}$ & $3.75 \times 10^{-6}$ & $1.10 \times 10^{-4}$ & $1.40 \times 10^{-4}$ & $9.59 \times 10^{-9}$ & $1.39 \times 10^{-5}$ & $5.76 \times 10^{-5}$ \\
\hline $1.81 \times 10^{-7}$ & $1.64 \times 10^{-5}$ & $3.53 \times 10^{-5}$ & $1.15 \times 10^{-5}$ & $1.33 \times 10^{-4}$ & $1.43 \times 10^{-4}$ & $7.94 \times 10^{-6}$ & $9.58 \times 10^{-5}$ & $9.11 \times 10^{-5}$ & $4.19 \times 10^{-8}$ & $1.20 \times 10^{-5}$ & $2.66 \times 10^{-5}$ \\
\hline $1.43 \times 10^{-7}$ & $1.12 \times 10^{-5}$ & $2.15 \times 10^{-5}$ & $1.03 \times 10^{-5}$ & $1.38 \times 10^{-4}$ & $1.29 \times 10^{-4}$ & $7.86 \times 10^{-6}$ & $1.20 \times 10^{-4}$ & $1.19 \times 10^{-4}$ & $5.23 \times 10^{-8}$ & $1.75 \times 10^{-5}$ & $4.01 \times 10^{-5}$ \\
\hline $1.21 \times 10^{-7}$ & $7.22 \times 10^{-6}$ & $9.19 \times 10^{-6}$ & $7.43 \times 10^{-6}$ & $6.43 \times 10^{-5}$ & $6.48 \times 10^{-5}$ & $8.18 \times 10^{-6}$ & $8.37 \times 10^{-5}$ & $7.78 \times 10^{-5}$ & $5.79 \times 10^{8}$ & $8.68 \times 10^{-5}$ & $2.26 \times 10^{-5}$ \\
\hline
\end{tabular}


Computational complexity analysis (CCA) was evaluated for the proposed algorithm based on the average time taken to calculate unknown neurons in the ANN structure using the GNDO-SQP algorithm. The execution time of the ANN-GNDO-SQP algorithm for different values of the nonlinearity parameter and Hartmann electric number in the EHD flow problem in terms of minimum, mean, and standard deviations are shown in Table 8. The results showed the consistency and efficiency of the proposed algorithm. All calculations and evaluation for this research were performed on an HP laptop EliteBook 840 G2 with intel (R) Core (TM) i5-5300 CPU @ 2.30 GHz, 8.00 GB RAM, 64 bits, operating in Microsoft Windows 10 Education edition, running R2018a version of MATLAB.

Table 8. Computational complexity analysis of the proposed algorithm for different values of the nonlinearity parameter and Hartmann electric number.

\begin{tabular}{|c|c|c|c|c|c|c|c|c|}
\hline & & GNDO & & & SQP & & ANN-GNDO-SQP & ANN-PSO-IPA \\
\hline Cases & Min. & Mean & Std. & Min. & Mean & Std. & Min. & Min. \\
\hline$H a^{2}=\alpha=0.5$ & $4.6280 \mathrm{~s}$ & $5.297 \mathrm{~s}$ & $0.5796 \mathrm{~s}$ & $0.1180 \mathrm{~s}$ & $0.1467 \mathrm{~s}$ & $0.0255 \mathrm{~s}$ & $4.746 \mathrm{~s}$ & $5.6643 \mathrm{~s}$ \\
\hline$H a^{2}=\alpha=1.0$ & $4.5540 \mathrm{~s}$ & $4.7603 \mathrm{~s}$ & $0.1837 \mathrm{~s}$ & $0.1380 \mathrm{~s}$ & $0.1463 \mathrm{~s}$ & $0.0097 \mathrm{~s}$ & $4.692 \mathrm{~s}$ & $5.5877 \mathrm{~s}$ \\
\hline$H a^{2}=\alpha=2.0$ & $5.1220 \mathrm{~s}$ & $5.6727 \mathrm{~s}$ & $0.6375 \mathrm{~s}$ & $0.1360 \mathrm{~s}$ & $0.1733 \mathrm{~s}$ & $0.0499 \mathrm{~s}$ & $5.258 \mathrm{~s}$ & $5.5285 \mathrm{~s}$ \\
\hline$H a^{2}=6, \alpha=2$ & $4.5510 \mathrm{~s}$ & $4.6330 \mathrm{~s}$ & $0.0886 \mathrm{~s}$ & $0.1350 \mathrm{~s}$ & $0.1407 \mathrm{~s}$ & $0.0051 \mathrm{~s}$ & $4.686 \mathrm{~s}$ & $5.3493 \mathrm{~s}$ \\
\hline$H a^{2}=20, \alpha=1$ & $4.6200 \mathrm{~s}$ & $4.7697 \mathrm{~s}$ & $0.1690 \mathrm{~s}$ & $0.1340 \mathrm{~s}$ & $0.1668 \mathrm{~s}$ & $0.0642 \mathrm{~s}$ & $4.754 \mathrm{~s}$ & $5.5411 \mathrm{~s}$ \\
\hline$H a^{2}=50, \alpha=2$ & $4.5410 \mathrm{~s}$ & $4.5607 \mathrm{~s}$ & $0.0224 \mathrm{~s}$ & $0.1400 \mathrm{~s}$ & $0.1523 \mathrm{~s}$ & $0.0150 \mathrm{~s}$ & $4.681 \mathrm{~s}$ & $5.3898 \mathrm{~s}$ \\
\hline
\end{tabular}

\section{Conclusions}

In this paper, we analyzed the mathematical model of the electro hydrodynamic (EHD) flow of fluid in a circular cylindrical conduit with an ion drag configuration. The problem was modelled by the boundary value problem with strong nonlinearity due to the rational function form of the nonlinearity of the EHD flow's equation. The solution of such a nonlinear differential equation is always a difficult task for any traditional, as well as modern, numerical techniques. Therefore, to calculate the velocity profile of the EHD flow we designed a neuro soft computing technique based on artificial neural networks. Our key contributions are summarized as follows:

- We developed a neuroevolutionary soft computing paradigm to analyze the mathematical model of the electrohydrodynamic (EHD) flow of fluid in the circular cylindrical conduit by exploiting the global search efficiency of GNDO algorithm and local search support of SQP.

- The ANN-GNDO-SQP algorithm is an unsupervised learning mechanism that has a simple structure and is easy to implement. It does not require any prior information about the problem aside from the essential initial and terminal setting of parameters in GNDO-SQP for the execution.

- The design scheme known as the ANN-GNDO-SQP algorithm was implemented to study the effect of variations in the nonlinearity parameter and Hartmann electrical number on $w^{*}\left(r^{*}\right), w^{*^{\prime}}\left(r^{*}\right)$, and $w^{*^{\prime \prime}}\left(r^{*}\right)$ of the fluid.

- The results concluded that an increase in Hartmann electric number $\left(\mathrm{Ha}^{2}\right)$ with fixed values of nonlinearity parameter caused an increase in the velocity profile, while an increase in the nonlinearity parameter with a fixed Hartmann electric number possessed an inverse relation with the velocity of the fluid.

- The results obtained by the proposed algorithm were compared with the least square method and orthogonal Bernstein collocation method. Statistics showed that the ANN-GNDO-SQP algorithm overlapped the exact solutions and analytical solution with minimum absolute errors.

- The results of performance measures show that the proposed algorithm is accurate, reliable, and efficient in solving real-world problems. 
Author Contributions: Data curation, N.A.K.; formal analysis, N.A.K.; funding acquisition, F.K.A. and C.A.T.R.; investigation, N.A.K. and M.S.; methodology, N.A.K. and M.S.; project administration, M.S.; resources, F.K.A., C.A.T.R. and M.S.; software, M.S.; supervision, M.S.; visualization, N.A.K.; writing-original draft, N.A.K.; writing-review and editing, F.K.A., C.A.T.R. and M.S. All authors have read and agreed to the published version of the manuscript.

Funding: The APC was funded by the Dirección General de Investigaciones of Universidad Santiago de Cali under call No. 01-2021.

Institutional Review Board Statement: Not Applicable.

Informed Consent Statement: Not Applicable.

Data Availability Statement: The data that support the findings of this study are available from the corresponding author upon reasonable request.

Acknowledgments: This research was funded by the Dirección General de Investigaciones of the Universidad Santiago de Cali under call No. 01-2021.

Conflicts of Interest: The authors declare that they have no conflict of interest.

\section{References}

1. Saville, D. Electrohydrodynamics: The Taylor-Melcher leaky dielectric model. Annu. Rev. Fluid Mech. 1997, 29, 27-64. [CrossRef]

2. Taylor, G.I. Disintegration of water drops in an electric field. Proc. R. Soc. London. Ser. A Math. Phys. Sci. 1964, $280,383-397$.

3. Crowley, J.M.; Wright, G.S.; Chato, J.C. Selecting a working fluid to increase the efficiency and flow rate of an EHD pump. IEEE Trans. Ind. Appl. 1990, 26, 42-49. [CrossRef]

4. Seyed-Yagoobi, J.; Bryan, J.E.; Castaneda, J.A. Theoretical analysis of ion-drag pumping. IEEE Trans. Ind. Appl. 1995, 31, 469-476. [CrossRef]

5. Maugin, G.A.; Eringen, A.C. Electrodynamics of Continua; Springer: Berlin/Heidelberg, Germany, 1990.

6. Kim, S.C.; Chun, Y.N. CFD modelling of electrohydrodynamic gas flow in an electrostatic precipitator. Int. J. Environ. Pollut. 2009, 36, 337-349. [CrossRef]

7. Zamankhan, P.; Ahmadi, G.; Fan, F.-G. Coupling effects of the flow and electric fields in electrostatic precipitators. J. Appl. Phys. 2004, 96, 7002-7010. [CrossRef]

8. Driouich, M.; Gueraoui, K.; Sammouda, M.; Haddad, Y.M.; Aberdane, I. The effect of electric field on the flow of a compressible ionized fluid in a cylindrical tube. Adv. Studies Theor. Phys. 2012, 6, 687-696.

9. Chankin, A.; Coster, D.; Asakura, N.; Corrigan, G.; Erents, S.; Fundamenski, W.; Muller, H.; Pitts, R.; Stangeby, P.; Wischmeier, M. A possible role of radial electric field in driving parallel ion flow in scrape-off layer of divertor tokamaks. Nucl. Fusion 2007, 47, 762. [CrossRef]

10. Balland, P.; Süli, E. Analysis of the cell-vertex finite volume method for hyperbolic problems with variable coefficients. SIAM J. Numer. Anal. 1997, 34, 1127-1151. [CrossRef]

11. Naqwi, A.A.; Hartman, R.P.A.; Marijnissen, J.C.M. Basic studies of electrohydrodynamic atomization process using phase Doppler measurement technique. Part. Part. Syst. Charact. 1996, 13, 143-149. [CrossRef]

12. Sides, P.J. Calculation of electrohydrodynamic flow around a single particle on an electrode. Langmuir 2003, 19, $2745-2751$. [CrossRef]

13. Sugiyama, H.; Ogura, H.; Otsubo, Y. Fluid devices by the use of electrohydrodynamic effects of water. J. Appl. Fluid Mech. 2011, 4, 27-33. [CrossRef]

14. Edamura, K.; Otsubo, Y. A continuous ink jet device on the basis of electrohydrodynamic mechanism. J. Imaging Sci. Technol. 2004, 48, 148-152.

15. Arin, D.R.; Yeo, L.Y.; Friend, J.R. Microfluidic blood plasma separation via bulk electrohydrodynamic ows. Biomicrouidics 2007, $1,014103014113$.

16. Hou, M.; Chen, W.; Zhang, T.; Lu, K. Electric field controlled dilute-dense flow transition in granular flow through a vertical pipe. Powder Technol. 2003, 135, 105-111. [CrossRef]

17. McKee, S.; Watson, R.; Cuminato, J.A.; Caldwell, J.; Chen, M.S. Calculation of electrohydrodynamic flow in a circular cylindrical conduit. J. Appl. Math. Mech./Z. Angew. Math. Mech. 1997, 77, 457-465. [CrossRef]

18. Paullet, J.E. On the solutions of electrohydrodynamic flow in a circular cylindrical conduit. J. Appl. Math. Mech./Z. Angezw. Math. Mech. 1999, 79, 357-360. [CrossRef]

19. Mastroberardino, A. Homotopy analysis method applied to electrohydrodynamic flow. Commun. Nonlinear Sci. Numer. Simul. 2011, 16, 2730-2736. [CrossRef]

20. Hosseini, E.; Barid Loghmani, G.; Heydari, M.; Wazwaz, A.M. A numerical study of electrohydrodynamic flow analysis in a circular cylindrical conduit using orthonormal Bernstein polynomials. Comput. Methods Differ. Equ. 2017, 5, $280-300$.

21. Khan, N.A.; Jamil, M.; Mahmood, A.; Ara, A. Approximate solution for the electrohydrodynamic flow in a circular cylindrical conduit. Int. Sch. Res. Netw. 2012, 2012, 341069. [CrossRef] 
22. Moghtadaei, M.; Nik, H.S.; Abbasbandy, S. A spectral method for the electrohydrodynamic flow in a circular cylindrical conduit. Chin. Ann. Math. Ser. B 2015, 36, 307-322. [CrossRef]

23. Roul, P.; Madduri, H. A new approximate method and its convergence for a strongly nonlinear problem governing electrohydrodynamic flow of a fluid in a circular cylindrical conduit. Appl. Math. Comput. 2018, 341, 335-347. [CrossRef]

24. Roul, P.; Madduri, H.; Kassner, K. A sixth-order numerical method for a strongly nonlinear singular boundary value problem governing electrohydrodynamic flow in a circular cylindrical conduit. Appl. Math. Comput. 2019, 350, 416-433. [CrossRef]

25. Gavabari, R.H.; Abbasi, M.; Ganji, D.D.; Rahimipetroudi, I.; Bozorgi, A. Application of Galerkin and Collocation method to the electrohydrodynamic flow analysis in a circular cylindrical conduit. J. Braz. Soc. Mech. Sci. Eng. 2016, 38, 2327-2332. [CrossRef]

26. Rostamy, D.; Karimi, K.; Zabihi, F.; Alipour, M. Numerical solution of electrodynamic flow by using pseudo-spectral collocation method. Vietnam. J. Math. 2013, 41, 43-49. [CrossRef]

27. Bég, O.A.; Hameed, M.; Beg, T.A. Chebyshev spectral collocation simulation of nonlinear boundary value problems in electrohydrodynamics. Int. J. Comput. Methods Eng. Sci. Mech. 2013, 14, 104-115. [CrossRef]

28. Roul, P.; Madduri, H.; Kassner, K. A new iterative algorithm for a strongly nonlinear singular boundary value problem. J. Comput. Appl. Math. 2019, 351, 167-178. [CrossRef]

29. Akbar, N.S.; Raza, M.; Ellahi, R. Anti-bacterial applications for new thermal conductivity model in arteries with CNT suspended nanofluid. J. Mech. Med. Biol. 2016, 16, 1650063. [CrossRef]

30. Ghasemi, S.E.; Hatami, M.; Ahangar, G.R.M.; Ganji, D.D. Electrohydrodynamic flow analysis in a circular cylindrical conduit using least square method. J. Electrost. 2014, 72, 47-52. [CrossRef]

31. Margerison-Zilko, C.; Goldman-Mellor, S.; Falconi, A.; Downing, J. Health impacts of the great recession: A critical review. Curr. Epidemiol. Rep. 2016, 3, 81-91. [CrossRef]

32. Roul, P. A fourth-order non-uniform mesh optimal B-spline collocation method for solving a strongly nonlinear singular boundary value problem describing electrohydrodynamic flow of a fluid. Appl. Numer. Math. 2020, 153, 558-574. [CrossRef]

33. Roul, P.; Goura, V.P.; Kassner, K. A high accuracy numerical approach for electro-hydrodynamic flow of a fluid in an ion-drag configuration in a circular cylindrical conduit. Appl. Numer. Math. 2021, 165, 303-321. [CrossRef]

34. Khan, N.A.; Sulaiman, M.; Aljohani, A.J.; Kumam, P.; Alrabaiah, H. Analysis of multi-phase flow through porous media for imbibition phenomena by using the LeNN-WOA-NM algorithm. IEEE Access 2020, 8, 196425-196458. [CrossRef]

35. Waseem, W.; Sulaiman, M.; Kumam, P.; Shoaib, M.; Raja, M.A.Z.; Islam, S. Investigation of singular ordinary differential equations by a neuroevolutionary approach. PLoS ONE 2020, 15, e0235829. [CrossRef] [PubMed]

36. Ahmad, A.; Sulaiman, M.; Alhindi, A.; Aljohani, A.J. Analysis of temperature profiles in longitudinal fin designs by a novel neuroevolutionary approach. IEEE Access 2020, 8, 113285-113308. [CrossRef]

37. Zhang, Y.; Lin, J.; Hu, Z.; Khan, N.A.; Sulaiman, M. Analysis of Third-Order Nonlinear Multi-Singular Emden-Fowler Equation by Using the LeNN-WOA-NM Algorithm. IEEE Access 2021, 9, 72111-72138. [CrossRef]

38. Waseem, W.; Sulaiman, M.; Islam, S.; Kumam, P.; Nawaz, R.; Raja, M.A.Z.; Farooq, M.; Shoaib, M. A study of changes in temperature profile of porous fin model using cuckoo search algorithm. Alex. Eng. J. 2020, 59, 11-24. [CrossRef]

39. Huang, W.; Jiang, T.; Zhang, X.; Khan, N.A.; Sulaiman, M. Analysis of beam-column designs by varying axial load with internal forces and bending rigidity using a new soft computing technique. Complexity 2021, 2021, 1-19. [CrossRef]

40. Waseem, W.; Sulaiman, M.; Alhindi, A.; AlHakami, H. A soft computing approach based on fractional order DPSO algorithm designed to solve the corneal model for eye surgery. IEEE Access 2020, 8, 61576-61592. [CrossRef]

41. Khan, A.; Sulaiman, M.; Alhakami, H.; Alhindi, A. Analysis of oscillatory behavior of heart by using a novel neuroevolutionary approach. IEEE Access 2020, 8, 86674-86695. [CrossRef]

42. Khan, N.A.; Sulaiman, M.; Kumam, P.; Aljohani, A.J. A new soft computing approach for studying the wire coating dynamics with Oldroyd 8-constant fluid. Phys. Fluids 2021, 33, 036117. [CrossRef]

43. Eringen, A.C.; Maugin, G.A. Electrodynamics of Continua II: Fluids and Complex Media; Springer Science \& Business Media: Berlin/Heidelberg, Germany, 2012.

44. Zhang, Y.; Jin, Z.; Mirjalili, S. Generalized normal distribution optimization and its applications in parameter extraction of photovoltaic models. Energy Convers. Manag. 2020, 224, 113301. [CrossRef]

45. Khan, N.A.; Khalaf, O.I.; Romero, C.A.T.; Sulaiman, M.; Bakar, M.A. Application of Euler Neural Networks with Soft Computing Paradigm to Solve Nonlinear Problems Arising in Heat Transfer. Entropy 2021, 23, 1053. [CrossRef] [PubMed]

46. Jian, J.; Liu, P.; Yin, J.; Zhang, C.; Chao, M. A QCQP-based splitting SQP algorithm for two-block nonconvex constrained optimization problems with application. J. Comput. Appl. Math. 2021, 390, 113368. [CrossRef]

47. Angalaeswari, S.; Sanjeevikumar, P.; Jamuna, K.; Leonowicz, Z. Hybrid pipso-sqp algorithm for real power loss minimization in radial distribution systems with optimal placement of distributed generation. Sustainability 2020, 12, 5787. [CrossRef]

48. Kim, R.; Lima, F.V. A Tchebycheff-based multi-objective combined with a PSO-SQP dynamic real-time optimization framework for cycling energy systems. Chem. Eng. Res. Des. 2020, 156, 180-194. [CrossRef]

49. Pirralha, A.; Weber, W. Correction for measurement error in invariance testing: An illustration using SQP. PLoS ONE 2020, 15, e0239421. [CrossRef]

50. Gao, B.; Hu, G.; Li, W.; Zhao, Y.; Zhong, Y. Maximum Likelihood-Based Measurement Noise Covariance Estimation Using Sequential Quadratic Programming for Cubature Kalman Filter Applied in INS/BDS Integration. Math. Probl. Eng. 2021, 2021, 9383678. [CrossRef] 